\title{
₹USGS
}

\section{The Constraints of Connecting Children with Nature- A Research Literature Review}

By Phadrea D. Ponds and Rudy M. Schuster

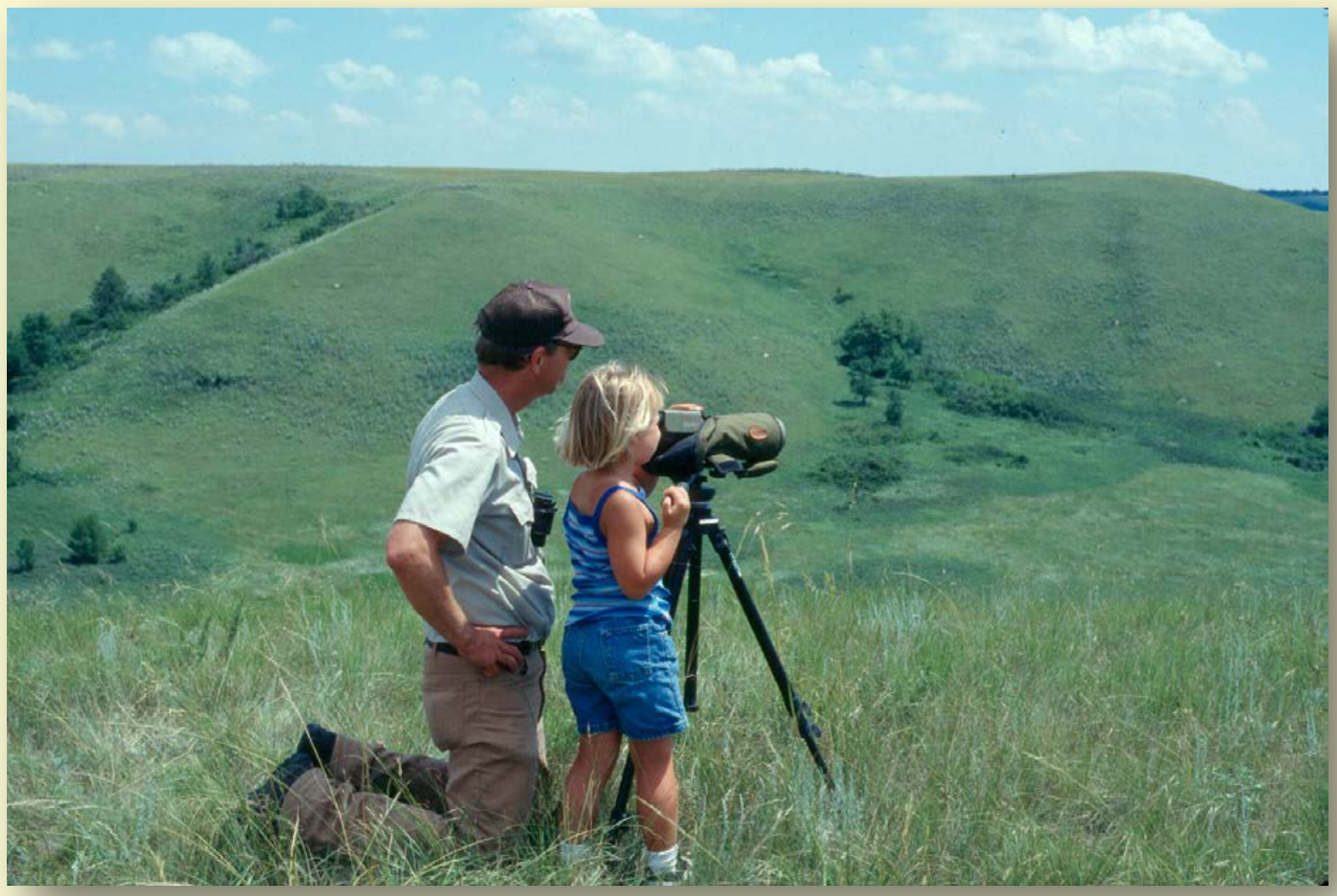

Open-File Report 2011-1139

U.S. Department of the Interior

U.S. Geological Survey 


\section{U.S. Department of the Interior \\ KEN SALAZAR, Secretary}

\section{U.S. Geological Survey \\ Marcia McNutt, Director}

U.S. Geological Survey, Reston, Virginia 2011

For product and ordering information:

World Wide Web: http://www.usgs.gov/pubprod

Telephone: 1-888-ASK-USGS

For more information on the USGS-the Federal source for science about the Earth, its natural and living resources, natural hazards, and the environment:

World Wide Web: http://www.usgs.gov

Telephone: 1-888-ASK-USGS

\section{Suggested citation:}

Ponds, P.D., and Schuster, R.M., 2011, The constraints of connecting children with nature-A research literature review: U.S. Geological Survey Open-File Report 2011-1139, 54 p.

Any use of trade, product, or firm names is for descriptive purposes only and does not imply endorsement by the U.S. Government.

Although this report is in the public domain, permission must be secured from the individual copyright owners to reproduce any copyrighted material contained within this report. 


\section{Contents}

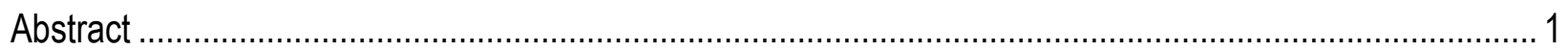

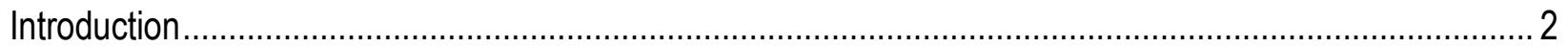

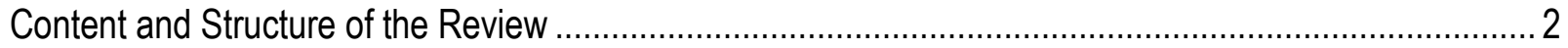

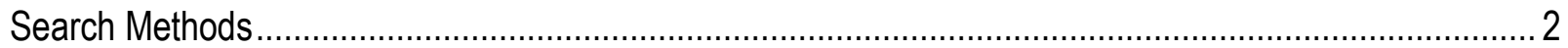

The Annotated Bibliography ..................................................................................................... 4

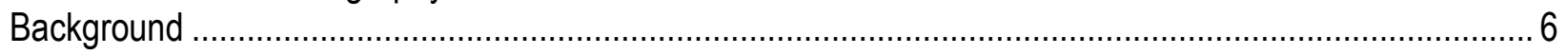

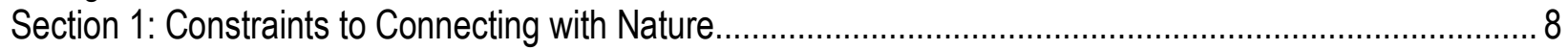

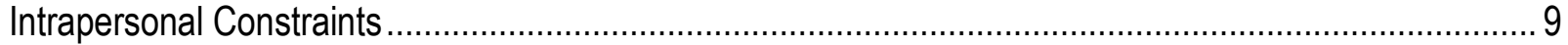

Interpersonal Constraints ..................................................................................................... 10

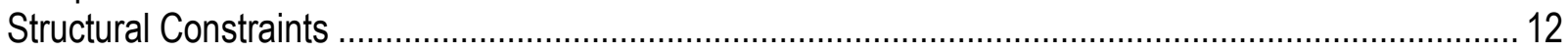

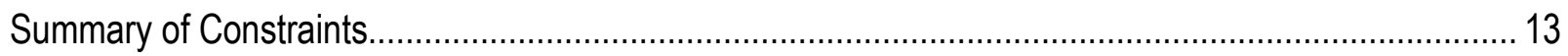

Section 2: Environmental Attitudes, Beliefs, and Values ....................................................................... 14

Summary of Environmental Attitudes, Beliefs, and Values ............................................................ 17

Section 3: Environmental Knowledge and Behaviors ……............................................................. 18

Summary of Environmental Knowledge and Behaviors .................................................................. 20

Section 4: Significant Life Experiences......................................................................................... 21

Summary of Significant Life Experiences on Environmental Behavior ................................................ 23

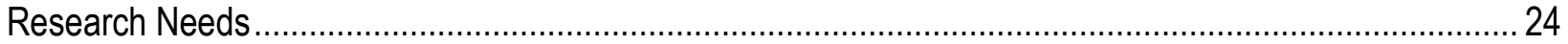

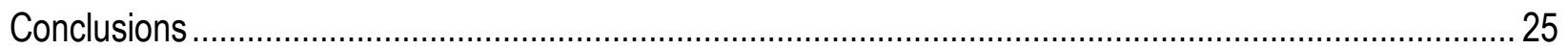



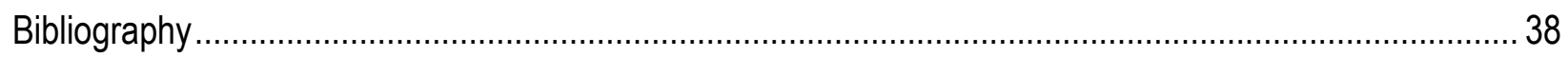

\section{Figures}

1. The Hierarchical Model of Leisure Constraints, adapted from Jackson and Scott (1999) .................... 4

2. Model adapted from an explanation by Hungerford and Volk, 1990, and Howe and Disinger 1988)

\section{Tables}

1. The search methods used for this review..............................................................................

2. Childhood play environment clusters: Study 1-Southeastern secondary school sample................... 15

3. Childhood play environment clusters: Study 2-Texas middle school sample ...................................16 


\title{
The Constraints of Connecting Children with Nature- A Research Literature Review
}

\author{
By Phadrea D. Ponds and Rudy M. Schuster
}

\begin{abstract}
Reports or research investigations studying children in nature are rapidly expanding and increasingly diverse. This document reports a review of a particular part of this field-studies of constraints to recreation and participation in environmental and outdoor recreation programs. The findings result from a review of more than 125 journal articles, books, and reports that were published between 1980 and 2009. This report discusses how the current information concerning constraints to participation can be understood in terms of four concentrations or foci of work generated in this particular field of study. These foci, which are all well established in the literature, are (1) intrapersonal, interpersonal, and structural constraints, (2) significant life experiences, (3) environmental attitudes, values and beliefs, and (4) environmental behaviors. The recent research associated with each of these research areas is discussed in successive sections of the review.

Overall, this review found that the research on constraints that inhibit children's connection to nature is less diverse in terms of methodological and theoretical approaches than is the research into the broader outdoor recreation research field within which it is situated. This review focused on the issue of connecting children with nature, but examples from studies using adults to understand childhood experiences and recreation preferences were used because there are relatively few peer-reviewed articles showing the theoretical or empirical connection of children and nature. In some cases, broader empirical studies were used to connect with larger themes (that is, environmental attitudes, beliefs, and values).
\end{abstract}




\section{Introduction}

\section{Content and Structure of the Review}

In an article on literature reviews, Bassey (2000, p. 25) distinguished among three types of review: (1) annotated bibliographies - listings, probably alphabetically arranged, possibly in sections, of literature sources in a particular area with a very brief account of what claim to knowledge is made; (2) academic reviews - an analytical account of the state of public knowledge of the topic (and noting areas of lack of knowledge), and (3) user reviews - a form of professional paper that arises from an academic review and which is devised and written by researchers and users working together. This report contains an academic review and an annotated bibliography. At a general level, there were many more studies focused on investigating characteristics of constraints in recreation than there were on the process of overcoming the constraints of connecting children with nature. This is reflected by the structure of the current review, which presents four themes found throughout the literature:

1. Structural, intrapersonal, and interpersonal constraints;

2. Significant life experiences that affect the human connection with nature;

3. Environmental attitudes, beliefs, and values; and

4. Environmental knowledge and behavior.

\section{Search Methods}

To complete this review, priority was given to literature on the subject of children in nature and the broader subject of significant life experience that are key to developing environmental attitudes, values and beliefs. Relevant literature was identified from a number of different sources. Bibliographic searches were undertaken, using several educational research databases (such as the Academic Primer, Web of Science, ERIC, Sage, and EBSCO). The following key terms were used to construct the literature search for this review: environmental education, outdoor education, children in nature, significant life experiences, environmental values (beliefs and attitudes), environmental knowledge, and constraints to recreation. These yielded a large number of titles that were then selected manually on the basis of abstracts and descriptors. These database searches were supported by manual searches of the contents of key research journals in the field (for example, The Journal of Environmental Education, Journal of Leisure Research, Environment and Behavior, and so forth) and previously published reviews and bibliographies on the subject of children in nature and the broader subject of perceived opportunities (or constraints) that are used to develop environmental and nature-related experiences. The selection criteria for this literature review are listed in table 1.

Searching of relevant materials was an ongoing process. Reading selected publications led to the identification of further references of potential relevance. Internet searches also generated a list of research articles not found in the databases listed above. Searching continued until no new or relevant citations arose that were not already identified. The primary criterion for selecting the material to include in this review were that each article had to address one of the four foci area mentioned herein. After selecting relevant materials, individual publications were reviewed and annotated. In all, 129 publications and 40 annotated citations were included in this review, the majority of them journal articles, along with a small number of books and research reports. 
Table 1. The search methods used for this review.

$\begin{array}{ll}\text { Overall focus: } & \begin{array}{l}\text { Empirical studies on environmental (and outdoor) education programs, } \\ \text { outdoor recreation experiences, environmental attitudes and behaviors } \\ \text { (when possible in the context of outdoor environmental education) }\end{array} \\ \text { Time scale: } & \text { Work published } 1980 \text { through } 2009 \\ \text { Age range: } & \begin{array}{l}\text { Primarily school-aged students (primary and secondary), high-school- } \\ \text { aged students, and studies using adult survey respondents }\end{array} \\ \text { Geographical scope: } & \begin{array}{l}\text { Primarily studies conducted in the United States (and only articles } \\ \text { published in English; one study conducted in the United Kingdom was } \\ \text { used) }\end{array} \\ \text { Sources: } & \begin{array}{l}\text { Peer-reviewed published articles, books, government reports, and to a } \\ \text { lesser degree very relevant popular magazine articles }\end{array} \\ \text { Databases: } & \text { Academic Primer, ERIC, SAGE, Web of Science, EBSCO }\end{array}$

The goals and objectives of this review were to identify and synthesize as many sources in the literature regarding the constraints related to connecting children with nature. This review found that complex social, cultural, and individual issues were associated with connecting children with nature. Also revealed in the literature was the suggestion that these issues should be considered when creating new initiatives to connect children with nature. The findings and recommendations reported in this review could be used to inform future discussions about the effects of constraints limiting a child's ability to connect with nature.

In order to organize and facilitate the in-depth discussion of different constraints, a hierarchical model of leisure constraints proposed by Jackson and Scott (1999) was used (fig. 1). The objective of adopting this model was to organize the literature review and provide a framework for presenting the results. The Hierarchical Model of Leisure Constraints and the associated research publication litany provide theoretical and operational definitions that are used throughout this literature review. As previously stated, this review focused on the issue of connecting children with nature, but examples from studies using adults to understand childhood experiences and recreation preferences were used because relatively few peer-reviewed articles show the theoretical or empirical connection of children and nature. The constraints model has been applied to both children and adults. Adopting this model allows us to present the literature in an understandable format and relate it to potential researchers in a meaningful way.

The underlying premise of the constraints model is explained by Crawford and others (1991) and in Jackson and Scott (1999). In order to understand the idea contained in the model, one must accept the notion that leisure participation is heavily dependent upon a person's ability to negotiate through a hierarchical sequence of factors (or constraints) before any level of participation is achieved. The hierarchical nature of this model begins with intrapersonal constraints that affect recreation preferences, and leads to structural constraints, which affect participation (Schroeder and others 2008).

According to Jackson (1990), leisure constraints are those factors that limit the formation of leisure preferences and inhibit (or prohibit) participation and enjoyment in leisure activities. The model identified three types of constraints to leisure: intrapersonal, interpersonal, and structural. Intrapersonal constraints involve psychological conditions that are internal to the individual such as personality factors, attitudes, or more temporary psychological conditions 
Figure 1. The Hierarchical Model of Leisure Constraints, adapted from Jackson and Scott (1999).

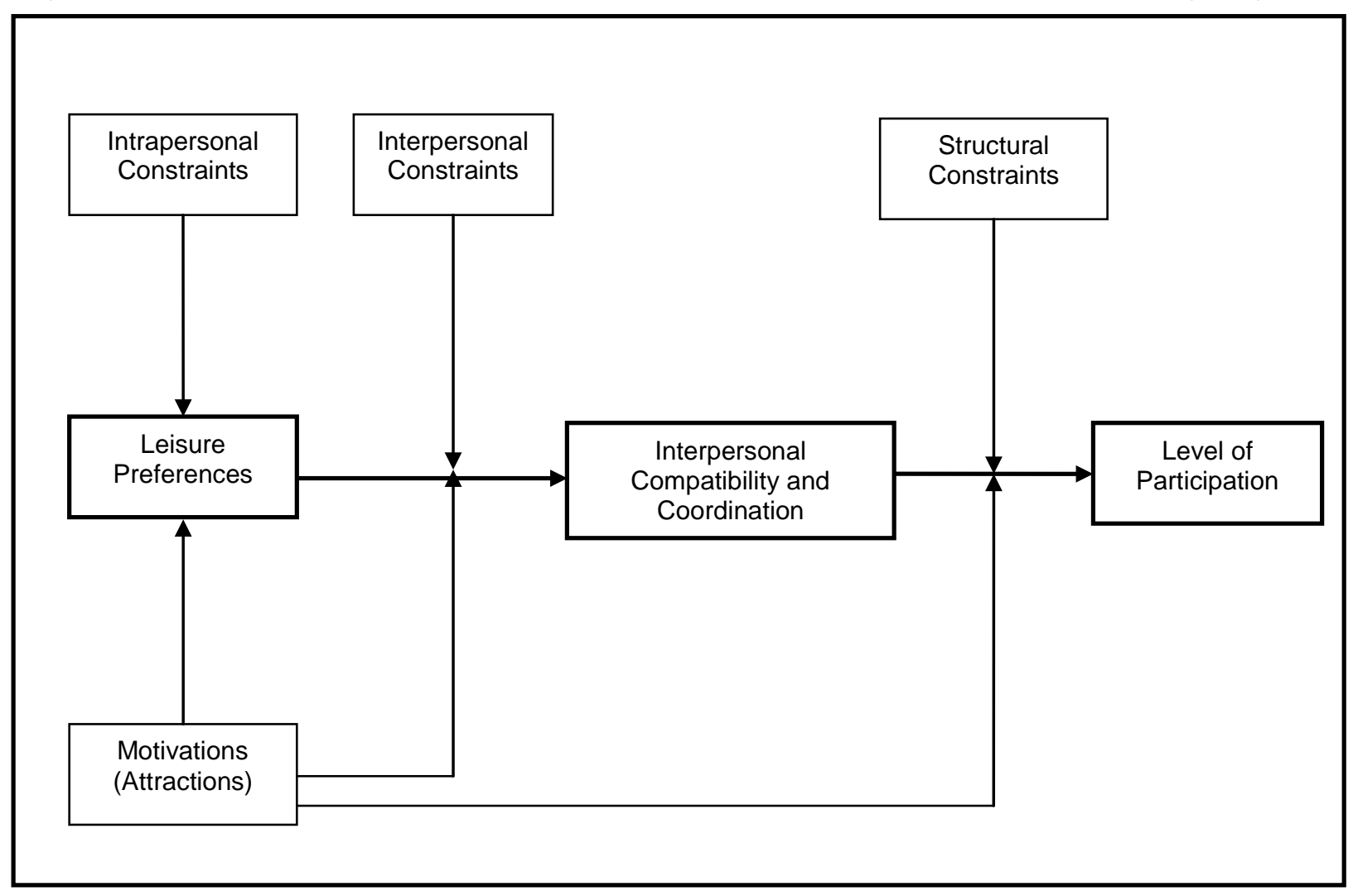

such as mood and lack of interest. Interpersonal constraints are those that arise out of interaction with others such as family members, friends, coworkers, and neighbors. Structural constraints include factors such as the lack of opportunities, difficulty of access, or the cost of activities that result from external conditions in the environment (Chick and Doug, 2003).

\section{The Annotated Bibliography}

This literature review and annotated bibliography is a direct response to a U.S. Fish and Wildlife Service request for information concerning the issues of connecting children with nature. The bureau faces a twofold challenge: finding ways to connect children to the outdoors by appealing to their own nature traditions, and giving families more opportunities - and reasons - to integrate the outdoors into their personal lives. In meeting each challenge, this report focused primarily (though not exclusively) on children, the conservation leaders of the future.

Several manuscripts, books, and published articles have been written in the past but may not be easily accessible to managers and planners of the agency. The bibliography in this document is not exhaustive because it was difficult to draw a clear boundary around the issue of "connecting children with nature" as a policy or a research domain. The articles selected for the bibliography are examples of literature on intrapersonal, interpersonal, and structural constraints that have direct relevance to the issue of connecting children with nature; furthermore, the 
bibliography is intended to demonstrate the breadth of the issues to illustrate multifaceted and interdisciplinary nature of connecting children with nature.

References selected for inclusion in the annotated bibliography generally contained information discussing the formative experiences children had in developing environmental attitudes and behavior (and in some cases adult recollections of childhood experiences), basic themes that concerned leisure preferences and constraints.

The geographic scope of the annotated bibliography was limited to substantive research studies within the United States. There were many studies available from the UK and Canada. These were not used in this review because the articles focused on environmental education programs or studies that were limited in the scope of understanding constraints of leisure.

Several sources were used to locate and obtain the references for inclusion in this annotated bibliography. References contained within the U.S. Geological Survey Policy Analysis and Science Assistance (PASA) database of recreation literature were examined for the applicability to this project. These sources provided the initial review of references. Searches in electronic databases provided most of the references contained in this review. Many of the reviewed references were located by examining Literature Cited section of papers under review for this project. Several unpublished lists of references were reviewed to cross-list the citations for applicable sources of additional information. Most of the studies in this review were published in research journals but also included occasional or special reports. This annotated bibliography does not review all of the references on connecting children with nature but reflects a review of the studies that, when combined, offer an understanding of the complex nature of the issue. Copies of the reviewed references are on file in the offices of the Policy Analysis and Science Assistance Branch at the USGS Fort Collins Science Center, in Fort Collins, Colo. 


\section{Background}

There is virtually unanimous agreement on the importance of connecting children with nature, and the recent push to facilitate this connection is especially relevant to natural resource managers, planners, and environmental educators. However, educators, managers, and planners are continuously challenged by changes in recreation trends and management policies. Despite the plethora of challenges related to finding ways to connect children with the outdoors, physical and hands-on participation in nature-based programs or outdoor recreation activities appeared to be the overarching theme of the recreation literature (Romsa and Hoffman, 1980). The growing body of qualitative research suggested that children have an innate need to connect with nature (Cohen, 1992; Fjortoft and Sageie, 2000; Moore, 1986; Sebba, 1991) and that there is a correlation between the amount of direct contact children have with the natural environment and their affinity for other living things in nature (Foster and Linney, 2007; Palmer, 1993; Wells, 2000; Musser and Malkus 1994). Research from the mid-1990s to the late 2000s showed an emerging pattern of children spending less time outdoors (Aitken, 1994; Gaster, 1991; Hillman and Adams, 1992; Moore, 1997; Hinniger, 1994; Nabhan,1994; Tanner 1998; Valentine and McKendrick, 1997). More recent literature from the 2000s suggest that children are spending less time outdoors because their access to nature is rapidly diminishing (Faber-Taylor, and others, 2002; Kahn, 2002; Karsten and van Vliet, 2006; Kellert, 2002; Louv, 2005; Pyle, 2002; Spencer and Woolley, 2000).

The culture where children played outside is almost gone, and everyday life has shifted indoors (Moore, 2004). As a result, direct and spontaneous contact with nature is fast becoming a missing part of the childhood experience (Malone and Tranter, 2003). Not only have children's regular unsupervised play in the outdoor natural world declined in the last few decades, but also, according to Pyle (1993), we are fast approaching an "extinction of experience," which breeds apathy toward the environment. The growing concern that children are spending less unsupervised play time outdoors has fueled a new movement billed "No Child Left Inside." This movement began after the publication of Louv's (2005) "Last Child in the Woods." Louv described the current disconnect from nature as a nonmedical condition called "nature deficit disorder." The term nature deficit disorder has been used to describe the shift from unstructured play time outdoors to highly regimented play indoors and structure time in outdoor team sports. The result is that children are no longer connected with the natural environment, and according to Louv, this condition may increase the occurrence and severity of behavioral, emotional, and physical disorders.

How much physical time is needed for a child to achieve or maintain a connection with nature is still in question. However, research on significant life experience has found that positive experiences in natural environments has the potential to promote a future desire to be connected with nature (Cachelin and others, 2009; Foster and Linney, 2007; Kaplan, 1995). Generally speaking, children who are exposed to the outdoors early in life tend to have increased significant life experience leading toward positive environmental attitudes, beliefs, and values when they reach adulthood (Chenoweth_and Gobster, 1990).

Fundamentally, the notion that connecting children with nature is largely an environmental education outreach initiative shaping the attitudes, beliefs, and values of children - thus creating a need to connect with nature - is a major focus of many environmental education programs. However, many nonenvironmental education practitioners struggle to determine which skills and tools are needed to provide young children with the most awareness 
and knowledge of nature. These practitioners understand that children today spend more time indoors watching television, playing video games, and otherwise using electronic media (Hofferth and Curtin, 2006); and that the emerging generation of children lack a sense of appreciation for the natural world largely because they do not get out to experience it as much as children from past generations once did (Kimbell and others, 2009; Clements, 2004; Kellert, 2005; and Louv, 2005).

The question researchers like David Sobel (1990) and Searle and Jackson (1985b) asked was "how could practitioners provide experience for children so that they will grow up to behave in environmentally responsible ways?" Sobel (2008) suggested that children need experiences that transcend learning facts about nature and that all too often those working with children are busy explaining the facts of nature instead of using real-life observations to enhance children's experiences. Once children are in elementary school (approximately 5 to 11 years old) they have access to many concrete experiences; however, mentors - adults who demonstrated a way of being in nature - were noted as being more helpful in the children's ability to learn about natural processes and the natural environment (Phenice and Griffore, 2003).

An increasing body of literature points to the importance of significant life experiences (for example, educational, recreational, developmental, emotional, and so forth) that lead to an increased desire to connect with nature (Chawla, 2007; Foster and Linney, 2007; Kellert 2002 others, 2004; Kaplan, 1995; Romsa and Hoffman 1980). 


\section{Section 1: Constraints to Connecting with Nature}

The goal of this section was to identify a variety of constraints that are likely to influence a child's ability to connect with nature in the future. Research on leisure constraints is not new. Forty years ago, the Outdoor Recreation Resources Review Commission (ORRRC) set the standard for assessing the effects of institutional constraints to participation in outdoor recreational activities (Betz, 1999). The ORRRC study asked questions that measured the effectiveness of services that could be quantified on an item-by-item basis. The intended results of ORRRC study were to be used by recreation managers to explain socioeconomic and demographic characteristics or recreation patterns of the day (Scott and Kim, 1998).

Leisure constraints began to be systematically investigated in the 1980s. At that time, constraints were closely related to "barriers" that existed between a person's desire to participate actively in a leisure activity and his/her actual participation (Scott, 2005). The early premises for constraint research stemmed from the belief that if constraints perceived as insurmountable were removed, participation or visitation would increase (Crompton and Kim, 2004). These early assumptions of constraints research were that people who participated in an activity were unconstrained and those who did not were constrained by default (Jackson and Dunn, 1991). However, Godbey (1994) pointed out that all of us are subjected to constraints, and limitations can be successfully negotiated to reach leisure goals. Crawford and others (1991) introduced a hierarchical model of leisure constraints including (1) intrapersonal constraints, which included negative individual psychological states and (or) other characteristics of an individual that interact with personal preferences (for example, self esteem and perceived physical skills); (2) interpersonal constraints, which stemmed from interactions and relationships among individuals (for example, access to partners' or friends' company for leisure activities); and (3) structural constraints, which intervened between leisure preferences and participation (for example, costs of participating and problems with facilities). This characterization of leisure constraints continued to be reflected in subsequent research by Backman (1991), Henderson and others (1998), Hultsman (1995), and Jackson and Dunn (1991).

Shaw and others (1991) examined internal (for example, personal skills, abilities, health) compared to external (for example, time, money, transportation) constraints. Stodolska (1998) divided constraints into "static" factors such as discrimination or access, which remain relatively stable over time, and "dynamic" factors such as weather, which change over time. Walker and Virden (2005) introduced a revised constraints model incorporating intrapersonal, interpersonal, and structural constraints, motivations, negotiation, along with socio-demographic and attitudinal factors to predict recreation participation. They subdivided structural constraints to outdoor recreation into four categories: (1) natural environment structural constraints, (2) social environment structural constraints, (3) territorial structural constraints, and (4) institutional structural constraints (Schroeder and others 2008).

In the early 1990s, researchers began to dismiss this assumption that intuitional or structural constraints were not insurmountable as previously considered. Reports showed that individual participants negotiated constraints as intervening constraints rather than insurmountable constraints to participation (Kay and Jackson, 1991; Scott, 1991; Shaw and others, 1991; Crawford and Godbey 1987, Crompton and Kim 2004). Jackson, Crawford, and Godbey (1993) found that rather than viewing structural constraints as insurmountable obstacles, intervening constraints should be conceptualized as having gradients of intensity and that people negotiate instead of reacting passively (for example, by not participating). Research by Jackson 
and others (1993) revealed that participation was not dependent on the absence of constraints but was modified based on negotiation strategies used to overcome constraints to participation. The constraints model continues to be used in leisure research to understand participation in leisure and recreation activities.

From the early assessments conducted by the ORRRC, research shifted from very specific and practical questions that could be used to assess the effects of institutional constraints to questions that explored a more academic understanding of the effects of interpersonal constraints on non-participation. This shift began a research trend recognizing that constraints were not only physical and external (facility, resource, and service-oriented), but also internal (for example, psychological) and social (for example, family and other interpersonal relations) (Scott and Kim, 1998).

Forty years after the ORRRC report Alan Ewert (2002) suggested that the state of outdoor recreation research had become more sophisticated and broader with the inclusion of other academic disciplines such as environmental psychology and social psychology. However, he questioned if current researchers were doing enough; basically, should the original questions concerning (recreational) carrying capacity be updated to address the "current social ills plaguing our society" (Ewert, 2002). Moving forward, Ewert (2002) recommended that modern researchers consider what function the themes of behaviors, values, outcomes (for example, family bonding, therapeutic value, or esthetic appreciation), urbanization and culture, and sense of place provide when studying the long-term effects of outdoor recreation research.

\section{Intrapersonal Constraints}

Researchers in the 1980s and early 1990s were are concerned about the intrapersonal constraints that limit or affect a person's desire to participate in specific activities (Backman and Crompton, 1989, 1990; Dunn, 1990; Francken and van Raiij, 1981; Godbey, 1985; Godbey, Graefe, and James, 1992; Howard and Crompton, 1984; Jackson 1990; Jackson and Dunn, 1988, 1991; Jackson and Searle, 1983; Searle and Jackson, 1985b; Schroeder and Wiens, 1986; Witt and Goodale, 1981). While these studies focused on the intrapersonal constraints of using of local parks and recreation services, they were used to serve as a basis for studies focused on the constraints of using regional and national parks (Godbey, 1985; Godbey, Graefe, and James, 1992; Howard and Crompton, 1984; Schroeder and Wiens, 1986,). Below is a list of intrapersonal constraints consolidated from the studies listed above.

The intrapersonal constraint reported most by nonusers of public recreation areas included fear of crime and safety concerns, lack of interest, lack of access, lack of information, and lack of transportation. Additional studies indicated that race, gender, and age were typically correlated with lack of financial resources, lack of time, fear of crime, lack of access, and lack of transportation (Scott and Jackson, 1996; Scott and Munson, 1994). Studies by Gobster (1998), Rideout and Legg (2000), and West (1989) pointed out that fear of crime and discrimination predominated as the barrier of nonuse by ethnic and racial minorities.

A study done by Floyd and others (1995 and 1994) examined how cultural constraints affected children's intrapersonal connections with nature. The researchers surveyed 1,200 students to study their predilections to connect with nature. The study found that AfricanAmerican students had a greater desire for modern comforts, and this had an opposite relationship with the desire for wildland environments. The study also showed that the white students had a stronger preference for wildland environments that was directly correlated with a preference for wildland activities. The results from this study (Floyd and others, 1995) have been 
supported by studies by other researchers. A study by Dwyer and Hutchinson (1990) revealed that African-Americans tended to prefer developed facilities and conveniences more than their white counterparts. Their results indicated that 53 percent of the African-Americans in their study showed a strong preference for developed facilities compared to 24 percent of the white respondents. Conversely, 57 percent of the white respondents showed a strong preference for preserved natural areas compared to only 27 percent of the African-American respondents.

Walker and others (2001) conducted another study of cultural constraints where they compared the differences between whites and Chinese in terms of motivations for outdoor recreation. The study was performed in a Canadian National Park located between two large Chinese and white communities. Members of each racial group were surveyed to determine their motivations for engaging in outdoor recreational activities. The study found that peoples' motivations for outdoor recreation correlated with their value system. The Chinese respondents preferred activities that coincided with values of group membership (for example, humility and modesty). On the other hand, the white respondents tended to prefer activities that coincided with autonomy/independence.

Finally, Irwin and others (1990) conducted a study comparing differences in environmental preferences between whites and Hispanics. This study was performed at a New Mexico campground. Here the researchers found that both whites and Hispanics preferred minimally developed campgrounds. However, they found that both groups had different interpretations of development. Those surveyed were asked to list their priorities in facilities and design when choosing a campground. Non-Hispanics listed quiet surroundings (24 percent), privacy (14 percent), water (14 percent), and space between campsites (13 percent) as their major priorities. Hispanic respondents listed toilets (39 percent), camping space at each site (25 percent), water (14 percent), and fire rings (8 percent). They also found that the non-Hispanic respondents preferred being far away from other campers more than Hispanics (67 percent and 28 percent, respectively) (Irwin and others, 1990). Other studies were also conducted concerning racial/ethnic differences in terms of motivations for using outdoor recreational facilities.

The overwhelming evidence provided by these studies show that there are, in fact, differences in outdoor recreation preferences between whites and minorities. As illustrated in figure 1, preferences and intrapersonal constraints are linked and facilitate or inhibit participation in leisure activities. The research suggests that these differences are real and that various segments of society prefer engaging with nature using different styles and or at varying degrees of receptivity.

\section{Interpersonal Constraints}

Research that linked socioeconomic status (SES) and leisure constraints documented the lack of financial resources as a significant interpersonal barrier among individuals with lower incomes and lower levels of education (Searle and Jackson, 1985a; Scott and Munson, 1994; Brown and others, 2001; Howard and Crompton, 1984; and Godbey and others 1992). Studies by Scott and Munson (1994) and Scott and Jackson (1996) reported that parents who were financially challenged and lacked the resources to try out new recreational activities with their children had limited knowledge of what leisure services, activities, and locales are available at little or no cost. In a study by Scott and Munson (1994) costs were seen as particularly problematic for homemakers, full-time employees, and people who had older children living at home. 
A variety of studies have shown that time constraints were the most frequently mentioned interpersonal constraint for nonparticipation in outdoor recreation activities (Jackson and Dunn, 1991; Jackson, 1994; Scott, 1993) and for not using local park and recreation services (Scott, 1993; Scott and Jackson, 1996). Other studies confirm that American children suffer from time constraints (Louv, 2005; Walker and Virden, 2005). Surprisingly, these studies reported that children have limited outdoor participation because they lack free time. As children are spending increasingly less time outdoors interacting with nature, the influence of media increases as a medium for children to interact with nature, thus increasing the need to reexamine how to address environmental education (Hudson, 2001).

Some researchers (Floyd, 1998; Philipp, 1995 and 1999; Stodolska, 1998) found that participants' race and acculturation level may also affect their perception of constraints. Several social theories have been developed to study the interpersonal constraints to participation in outdoor recreation, particularly ethnic and racial minority groups (Johnson and others, 1999). The most prevalent is the Marginality Theory (Washburne, 1978). The constraints associated with the marginality theory are the same interpersonal constraints identified in studies conducted with nonminority participants: lack of access to transportation, underdeveloped program availability, and lack of information about facilities (Chavez, 2000; Johnson and others, 1998 and 1999). However, in the United States, studies demonstrated that marginality as an interpersonal barrier to recreation participation is more likely intensified among underserved minorities than whites (Floyd and others, 1993; Tierney and others, 1998; Johnson and others, 1998; Bowker and others, 1999, Philipp, 2000).

In a study conducted by the Centers for Disease Control (2003), parents were asked about their perceptions of five potential barriers to their children's participation in physical activities: transportation problems, lack of opportunities to participate in physical activities in their area, expense, parents' lack of time, and concerns about neighborhood safety. Although all parents in the study perceived these as constraints to participation, concerns about transportation, opportunities in their area, and expense were reported significantly more often by non-Hispanic black and Hispanic parents than by non-Hispanic white parents. Concerns about neighborhood safety were reported more frequently for girls (17.6 percent) than for boys ( 14.6 percent) and were reported more frequently by Hispanic parents (41.2 percent) than by non-Hispanic white (8.5 percent) and non-Hispanic black (13.3 percent) parents. Overall, parents with lower incomes and education levels reported more constraints (Centers for Disease Control, 2003).

With only 24 hours in a day, examining how children spend their time could provide basic information needed to understand what parents and society value, and what changes may be occurring over different generations. Despite the importance of this topic, very few studies have been conducted in this area, and even fewer have been conducted that looked at changes over time). The statistics highlighted below suggest children's lives have become increasingly structured and media oriented.

- Children today spend less time playing outdoors than any previous generation. Many parents today are bombarded with media reports of "stranger danger" even though childhood abduction rates are actually down by about 40 percent over previous generations. Eighty-two percent of mothers with children between the ages of 3 and 12 cited crime and safety concerns as one of the primary reasons they do not allow their children to play outdoors (Clements, 2004). 
- More than 60 percent of children between the ages of 9 and 13 do not participate in any organized physical activity outside of school. Nearly one-fourth get no free-time physical activity at all (Centers for Disease Control, 2003).

- Children's free play and discretionary time declined more than 7 hours a week from 1981 to 1997 and an additional 2 hours from 1997 to 2003, totaling 9 hours less a week of time over a 25-year period in which children participated in unstructured activities (Hofferth and Sandberg, 2000; Hofferth and Curtin, 2006).

- Children between the ages of 6 months and 6 years spend an average of 1.5 hours a day with electronic media, and youth between the ages of 8 and 18 spend an average of 6.5 hours a day with electronic media. (Rideout others, 2003).

The results are not surprising, and the problem is partly generational. In the 1900s more than 60 percent of Americans lived in rural areas or worked on a farm. By the 1970s 200 million Americans were living in urban areas and connection with the land became indirect and more recreational (Kimbell and others, 2009). By the early 1990s outdoor activities among children were low and declining, and Hofferth and Curtin (2006) found that the proportion of children aged 9-12 years who spent time on such outdoor activities as hiking, gardening, and fishing fell by 50 percent from 1997 to 2003 in just 6 years.

\section{Structural Constraints}

Structural constraints could include practices and attitudes that exclude or discourage children from participating in nature. Institutional practices occur when it is not clear which part of an agency is responsible for creating, maintaining, and sustaining an environmental education program. Interpersonal attitudes, values, or beliefs may hinder involvement in outdoor activities. Institutional constraints are considered to be formal or informal policies, rules, or laws that could limit a person's participation in recreation activities. A variety of articles are available that attempt to explain the institutional constraints that limit a person's use of public park and recreation amenities (Arnold and Shinew, 1998; Stankey, 1997; Godbey, 1985; Howard and Crompton, 1984; Jackson, 1983; Jackson, 1993; Scott and Jackson, 1996; Scott and Munson, 1994). Schroeder and others (2008) discussed four institutional factors that constrained outdoor recreation: (1) costs/regulations/crowding, (2) concerns about safety or discrimination, (3) planning required, and (4) access.

Based on a study for the Arizona Outdoor Recreation Coordinating Commission and the Arizona State Parks Board, Cardin (1994) underscored that understanding the constraints that keep children from participating in outdoor recreation activities is a key component in planning and providing outdoor recreation opportunities. Cardin pointed out that many outdoor recreation plans, particularly in Arizona's Statewide Comprehensive Outdoor Recreation Plans (SCORP), are geared toward the recreation needs of adults and do not incorporate the recreation needs of young people. Cardin (1994), surveyed 3000 school children (4-12 grades) in 31 communities throughout the State of Arizona. The study yielded more than 2,500 usable surveys. The children in this study were asked to describe the constraints that keep them from participating in outdoor activities and programs. The outdoor recreation participation constraints were dominated by issues related to time and cost. Nearly 40 percent of the children reported that their outdoor recreation activities were limited because they lack free time and their parents would not let them go to recreation areas because of the expense. 
Structural and organizational constraints are oftentimes unknowingly created by agencies that inhibit program access and opportunity to nontraditional, marginalized, and disenfranchised populations, including children (Allison and Hibbler, 2004). Coupled with the policies and rules, there may be a host of constraints manifested in the negative attitudes and stereotypes held by some management and staff that may help foster or reinforce the marginalization of these constituents (Allison and Hibbler, 2004). In recent years, there has been an increased recognition that institutional analysis is needed to examine the ways that recreation-related agencies and programs respond to nontraditional consumers (Allison, 1999, 2000; Floyd, 1998; Philipp, 1995; Scott, 2005). The research gap may be due, in part, to the assumption that such research is not needed because the recreation profession is founded on egalitarian principles which are translated into policies and procedures (Allison and Hibbler 2004). Jackson (1983) suggested that recreation service providers and planners should undertake various types of needs assessments in order to continuously monitor possible stereotypes that may keep them from meeting the needs and creating age appropriate activities for children and youth.

\section{Summary of Constraints}

In the literature on leisure constraints and constraint negotiation, constraints were typically portrayed as inanimate obstacles or conditions that can sometimes be overcome through individual effort and initiative. Negotiation of leisure constraints refers to the successful navigation of those obstacles. The constraints approach to understanding leisure is now commonplace when attempting to explain both nonparticipation and participation in leisure activities. Constraints are "factors that are assumed by researchers and perceived or experienced by individuals to limit the formation of leisure preferences and to inhibit or prohibit participation and enjoyment in leisure." Constraints research assumed that the basic human condition involves a desire or need to participate. If someone does not participate in an activity, it must be because they cannot (that is, nonparticipation = constraint), and if they do participate they must have overcome or "negotiated" constraints to achieve participation (that is, participation = negotiated constraint).

The literature supported the notion that leisure preferences are formed and participation in recreation takes place:

- when intrapersonal barriers are absent or have, with support, been overcome;

- when interpersonal barriers, related to interpersonal interaction, are absent or overcome; and

- when there are no insurmountable structural barriers, related to physical or material constraints on leisure participation, such as lack of money or transportation. While terms in the literature varied, intrapersonal, interpersonal, and structural constraints appeared to be directly related to connecting people with nature. Research should continue to examine how children function socially and academically while engaged in naturerelated programs. Specifically, attention should be paid to how and when intrapersonal, interpersonal, and structural constraints are negotiated by children. Additional research is needed that focuses on the practical implications and applications of the constraint literature. 


\section{Section 2: Environmental Attitudes, Beliefs, and Values}

The concept of environmental attitudes, beliefs, and values has been central to human dimensions research of natural-resource management for more than 30 years. The established research in this area primarily explains public attitudes and values toward wildlife (Kellert,1976;Kellert and Westervelt 1984; Purdy and Decker, 1989; and Tarrant and Green, 1999). However, as the concept evolved, researchers agree that the values toward wildlife have a potential function in the development of environmental attitudes and beliefs (Teel and others, 2005). Researchers and practitioners studying children in nature are concerned that the current disconnection of children with the environment will result in a generation of children and youth who misunderstand or have few connections to the natural world (Louv, 2005; Kimbell and others 2009) and will therefore have less of an opportunity to develop positive environmental attitudes, beliefs, and values (Kahn, 2002).

Robin Moore (2004) argued that the culture of playing outside is gone and children's everyday life has shifted to the indoors. Sandra Hofferth and John Sandberg (2000) cite the following statistics: between 1981 and 1997, the amount of time U.S. children aged 6-8 spent playing outdoors decreased by 4 hours per week while the amount of time they spent indoors in school increased by almost 5 hours per week. As a result, children's opportunity for direct and spontaneous contact with nature is a vanishing experience of childhood (Berenguer, 2007; Chawla, 1994a and 1994b; Kahn, 2002; Pyle, 2002; Rivkin, 1990; and Wilson, 1997).

Kahn (2002) also argued that modern technology can provide extraordinary access to images and recreations of nature; however, technology does little to offer the same emotional, cognitive, and psychological benefits as interactions with the natural environment (Kellert, 2005; Louv, 2005; Chawla, 2006; Faber-Taylor and Kuo, 2006). Cohen and Horm-Wingerd (1993) contend that when children obtained most of their attitudes and beliefs through electronic media their notions of the natural environment were typically unfounded misconceptions because they had very little physical contact with living things.

Finally, Kimbell and others (2009) emphasized that the technological know-how that distinguishes today's youth is often gained at the expense of ecological awareness and environmental literacy. They warned that a whole generation of Americans is growing up detached from nature.

Since many of today's children no longer spend long, unstructured hours playing outdoors, which would foster positive environmental attitudes, beliefs, and values, parents and teachers must now provide intentional experiences that give children the opportunity to understand and appreciate the natural world (White, 2001). Bixler and others (2002) noted that it is important for a child to receive messages that an interest in the outdoors is acceptable and desirable; in this way, the child receives further social reinforcement for holding an interest in nature. However, White and Stoeklin (2008) and Chawla (1994a and 2002) cautioned that opportunities to develop environmental attitudes, beliefs, values - separate from those of parents and teachers - must be developmentally appropriate because children experience the environment differently than adults. Research suggested positive environmental attitudes and beliefs grow out of children's regular contact with and play in the natural world (Berenguer, 2007). Bunting and Cousins (1985) list child-nature play, or unrestricted opportunities, for children younger than age 11 to explore in the natural environment as especially important for developing positive environmental attitudes, beliefs, and values. The best learning environments are informal and naturalistic outdoor naturescapes where children have unmediated opportunities 
for adventure and self-initiated play, exploration, and discovery (Bixler and Floyd, 1997; Corcoran, 1999; Ewert and others, 2005; Hinds and Sparks, 2008; Palmer, 1993; and Wells and Lekies, 2006). These informal experiences tend to stimulate a genuine interest in and valuing of environmental knowledge than is provided in more structured environmental education programs (Bixler and others, 2002).

A study by Ewert and others (2005) supported the idea that early childhood outdoor experiences (many of which are often recreational or done during leisure time) are directly related to the development of their environmental views as adults. More specifically, this study suggested that participation in early-life outdoor activities and exposure to media events focusing on environmental issues and witnessing negative environmental events are related to adults' current beliefs, attitudes, and values concerning the environment. Ewert surveyed 533 undergraduate students to determine if early-life environmental education had an influence on their current environmental beliefs and values. He found that early-life participation in programmed outdoor activities and education or involvement with organizations did not have a significant effect on advanced environmental values. However, appreciative outdoor activities, consumptive outdoor activities, media exposure, and witnessing negative environmental events explained 14 percent of the variance in their environmental values.

Bixler and others (2002) praised research suggesting that environmental attitudes and values probably begin to emerge in children as a function of a positive and affective attachment to wild places; however, they criticized studies that overemphasized the relationship between childhood play in wildland environments and an intellectual interest in environmental sciences or proenvironmentalism as an adult. Bixler and others (2002) argued that childhood play in wildland areas is more closely related to environmental attitudes than activism.

In their study, Bixler and others (2002) tested the relationship between frequency of childhood play in different physical environments and environmental preference within the "life domains" of education, recreation, and work. The authors conducted two surveys with middle and high school students, one in Kentucky and North and South Carolina $(\mathrm{N}=1,376)$ and the other in Texas $(\mathrm{N}=450)$. Lists of play environments were presented to the students to measure (on a 5-point scale) how often they played in different common outdoor environments before the age of 10. The results from both studies are listed in the tables 2 and 3.

Table 2. Childhood play environment clusters: Study 1-Southeastern secondary school sample.

\begin{tabular}{lcccc}
\hline Amount played & $\begin{array}{c}\text { Study } \\
\text { population } \\
\text { mean }\end{array}$ & $\begin{array}{c}\text { Wildland } \\
\text { adventurers } \\
(\mathbf{n}=\mathbf{4 9 3})\end{array}$ & $\begin{array}{c}\text { Urban } \\
\text { adventurers } \\
(\mathbf{n}=360)\end{array}$ & $\begin{array}{c}\text { Yard } \\
\text { adventurers } \\
(\mathbf{n}=\mathbf{4 5 5})\end{array}$ \\
\hline Around a pond or stream & 2.01 & 2.70 & 2.39 & 0.97 \\
In a farm field/pasture & 2.10 & 2.53 & 2.18 & 1.57 \\
In the woods & 2.23 & 3.14 & 2.37 & 1.14 \\
In an alley & 0.94 & 0.45 & 2.48 & 0.26 \\
In an empty lot & 1.19 & 0.82 & 2.36 & 0.67 \\
In a friend's yard & 3.44 & 3.32 & 3.78 & 3.31 \\
In my yard & 3.65 & 3.32 & 3.80 & 3.87 \\
In a playground & 2.89 & 2.46 & 3.30 & 3.04 \\
\hline
\end{tabular}

Data based on a 4-point scale, ranging from $0=$ never played to $4=$ almost always played.

From Bixler and others (2002) 
Table 3. Childhood play environment clusters: Study 2-Texas middle school sample.

\begin{tabular}{lcccc}
\hline Amount played & $\begin{array}{c}\text { Study } \\
\text { population } \\
\text { mean }\end{array}$ & $\begin{array}{c}\text { Wildland } \\
\text { adventurers } \\
(\mathbf{n}=133)\end{array}$ & $\begin{array}{c}\text { Urban } \\
\text { adventurers } \\
(\mathbf{n}=144)\end{array}$ & $\begin{array}{c}\text { Yard } \\
\text { adventurers } \\
(\mathbf{n}=156)\end{array}$ \\
\hline In the woods & 1.88 & 2.58 & 2.08 & 1.09 \\
Around a pond or lake & 2.02 & 2.68 & 2.30 & 1.19 \\
In an overgrown field & 1.82 & 2.42 & 2.12 & 1.03 \\
In a farm field/pasture & 1.92 & 2.65 & 2.30 & 0.96 \\
Around a stream or creek & 1.98 & 2.69 & 2.28 & 1.10 \\
In an alley & 0.89 & 0.59 & 1.063 & 0.46 \\
In a street & 2.44 & 1.44 & 3.26 & 2.53 \\
In a friend's yard & 3.08 & 2.56 & 3.47 & 3.16 \\
In my yard & 3.50 & 2.92 & 3.76 & 3.76 \\
In a playground & 2.69 & 2.23 & 2.81 & 2.99 \\
\hline
\end{tabular}

Data based on a 4-point scale, ranging from $0=$ never played to $4=$ almost always played. From Bixler and others (2002)

Bixler and others (2002) found that the children who ventured beyond their backyards and played in wild environments had more positive perceptions of natural environments, and outdoor recreation activities than the children who spent most of their play time in their back yards. Bixler and Floyd (1997) concluded that childhood play in natural environments was related to environmental competencies and preferences but were not directly correlated to an intellectual interest in environmental sciences or environmental activism.

In a study of 6th-grade students, Eagles and Demare (1999) found that a child's attitudes toward the environment correlated more with talking about the environment at home, watching nature films, and reading about the environment than attending a one-time environmental education program. In their study, 72 sixth-grade students, those without formal environmental education training, were surveyed before and after of a week-long environmental camp program. A pretest, given to the student a week before going to the camp, was used to measure the student's involvement in activities the authors considered influential to childhood environmental attitudes. A sample of the questions used for the pretest is listed below:

- Did you attend a summer camp this past summer?

- Do you go camping with your family at least once a year?

- Do you watch films or television programs with your family?

- Do you spend time in class talking about the environment?

- Do you read books or magazines on nature or the environment?

- Do you ever talk about the environment with your family?

The results from the pretest showed that the level of involvement in environmental activities varied from 31 percent, for attending summer camp the previous year, to 71 percent, for watching environmental television or movies. The authors conducted a difference-of-means test for attitude scores between students involved in an activity and those not involved. The test showed statistical significance for three activities: talking about the environment at home, 
reading environmental books or magazines, and watching environmental television or movies. Attending summer camp, camping with family, and talking about the environment in class did not have a significant correlation with their attitude score. The results of the post-tests revealed that camping during the week-long program did not affect the attitudes of the students. Admittedly, the authors were surprised by these results but concluded that low levels of environmental experience combined with low-level attitude scores are precursors to change (Eagles and Demare, 1999). The results of the study suggested that outdoor camping experiences created lasting gains in environmental knowledge but did not compare to the influence that family and media had in creating environmental attitudes.

\section{Summary of Environmental Attitudes, Beliefs, and Values}

Very little is known about how young children develop their environmental attitudes, beliefs, and values, and how children frame environmental issues for themselves and then translate their understanding into action. The literature on children's environmental attitudes and values focused on the ability children had to understand basic principles of nature. The topic of ongoing attention was found in the larger attitudinal literature that concerned adult participants.

The literature connected environmental attitudes to beliefs and applied values as a method to predict behavior. It was clear from literature that environmental education could affect a change in a child's environmental attitudes, beliefs and values. What was less clear, however, was the process needed to get from environmental education to the development of attitudes, beliefs and values concerning the environment that endure through adulthood. Additional research is needed to evaluate and define the tools and procedures necessary to influence longtermed modifications in environmental attitudes, beliefs, and values. 


\section{Section 3: Environmental Knowledge and Behaviors}

The term environmental behavior is found throughout the literature - it is defined as an environmental action taken based upon particular environmental attitude (Ewert and others, 2005; Kaiser and others 1999; Kollmuss and Agyeman, 2002; Thapa and Graefe, 2003). For nearly two decades, researchers have devoted themselves to studying environmental behavior by connecting environmental knowledge and attitude to environmental action (Arcury, 1990; Newhouse, 1990; Finger, 1994; Leeming and others, 1995). These studies showed that that knowledge alone does not necessarily lead to environmental action. The literature suggested that there is a connection between knowledge and attitude (Disinger, 1982; Hewitt, 1997; Jensen, 2002). Eagles and Demare (1999) noted that the research on the attitudes of children is a major contribution because the development of environmentally sensitive attitudes and values in youth is seen as important to environmental behavior later in life.

Hewitt (1997) argued that a fundamental part of any environmental education program should ultimately encourage responsible environmental behavior. But how does a child transfer environmental education (knowledge) into responsible environmental behavior? Researchers in the social sciences, natural resources, and human dimensions have sought to understand the factors that lead people to move (or to fail to move) from environmental knowledge to environmental behavior (Bradley and others, 1999; Courtenay-Hall and Rogers, 2002; Kollmuss and Aygeman, 2002). The most favored assumption builds upon the belief that education leads to greater awareness and consciousness leading toward an attitude change that ultimately improves the individual behavior (Adams and others, 1986; Ajzen and Fishbein,1980; Fishbein and Ajzen, 1974). Hungerford and Volk (1990) proposed that environmental behavior could be changed through education only if knowledge was not the single underpinning for change. Howe and Disinger (1988) underscored these conclusions suggesting that conceptual knowledge alone is not sufficient to generate responsible environmental behavior. Both researchers concluded that a combination of knowledge, skills (environmental problem solving), attitudes (environmental sensitivity), and action contributed to making a difference in developing responsible environmental behavior. Based on the research of Hungerford and Volk (1990) and Howe and Disinger (1988), the following model for developing environmental behavior is offered as a way to illustrate the gap between environmental knowledge and environmental behavior (fig. 2). Each variable in the model supports the premise that environmental knowledge should not be the limiting factor initiating environmental behavior. Knowledge should be taken together with skills, attitudes, and action to create environmental behavior as an outcome. The model starts with the relatively stable structure of environmental knowledge and moves toward the effects of more specific environmental attitudes, beliefs, values, environmental problem solving, and personal motivation to take action. These attributes when combined with knowledge might be parts of the puzzle that contribute to environmental behavior.

Urban and Martin (2008) used the Children's Environmental Attitude and Knowledge Scale (CHEAKS) to test the relationship between children's knowledge of environmental issues, their emotions regarding the environment, and their behavior toward the environment. In their study, Urban and Martin tested 136 students attending a week-long summer day camp in Anchorage, Alaska, one month after the end of the camp. The participants for this study were 72 girls and 63 boys between the ages of 6 and 13 years $(M=9.5)$. The students were separated into three age groups: the 6- to 7 -year-olds $(n=62)$, the 8 - to 9 -year olds $(n=56)$, and the 10 - to 
Figure 2. Model adapted from an explanation by Hungerford and Volk, 1990, and Howe and Disinger 1988).

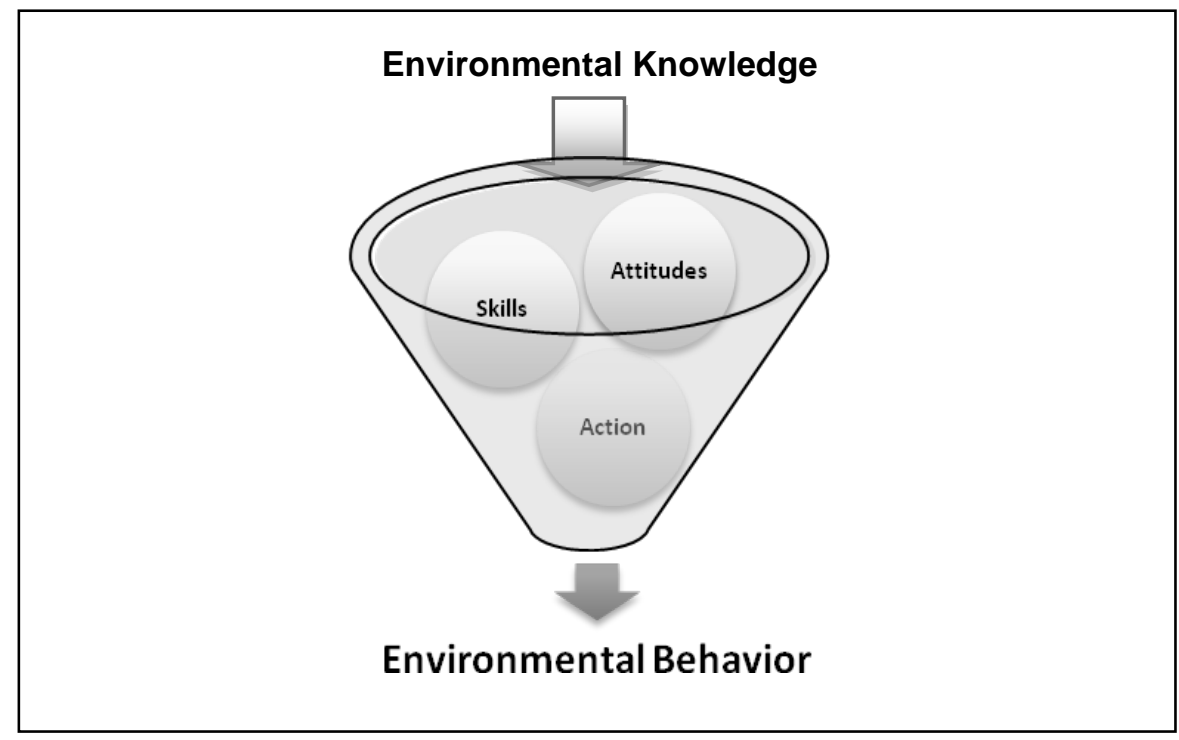

thirteen-year-olds ( $\mathrm{n}=17$ ). The CHEAKS scale was used to measure two subscales of attitude and knowledge. The attitude subscale consisted of 36 items to measure a student's attitudes toward environmental issues; the knowledge subscale consisted of 30 additional items to measure one of six themes: animals, energy, pollution, recycling, water, and general environmental issues. They found that there was a relationship between the child's age and the amount of knowledge they had about the environment. There was a limited relationship between knowledge and attitude; however, there was a correlation between knowledge and behavior. They concluded that effect may be a possible mediating factor in the progression of knowledge acquisition to the change in behavior.

In a second study, Smith-Sebasto and Semrau (2004) examined the New Jersey Conservation programs in terms of whether they were achieving their aim of changing participant's attitudes toward the environment. These programs were four days and three nights of outdoor education programs for sixth graders. The results of the study showed that the programs assessed were ineffective in altering students' overall attitudes but were assessed as being effective in increasing environmentally responsible behaviors. The most revealing outcome of this study was that knowledge of action strategies was needed to promote environmentally responsible behaviors and that knowledge about the environment is not enough.

Finally, the State of Wisconsin developed State curriculum guides that recognized the need to provide environmental learning in school programs, beginning in early grades and continuing the emphasis throughout the students' schooling (Engelson, 1985). The Wisconsin program supports a hierarchical approach: (1) environmental concepts, attitudes, and skills develop over time; (2) effective environmental programs involve both cognitive and affective emphases; (3) effective environmental education programs require issue analysis, and (4) environmental experiences should be provided that help the individual develop the feeling that their efforts and actions can make a difference with real issues and problems. 


\section{Summary of Environmental Knowledge and Behaviors}

Environmental research has focused on the attitudes, knowledge, and behaviors of adults for several decades. There has been substantial research compiled looking at recreational activities and demographic variables, in relation to their environmental attitudes and behaviors. Unfortunately there were very few up-to-date, empirical studies published that discussed the relationship between environmental behaviors and knowledge in children (Culen and Volk 2000).

While the available articles demonstrated that knowledge is one component needed to change environmental attitudes, quantifiable effects of programs connecting children's knowledge with behavior would be useful. Additional studies are needed to measure:

1. the extent to which behaviors could be changed or reinforced based on the environmental knowledge or experiences gained during an environmental education program; and

2. the extent to which increased environmental knowledge could alter children's long-term support of nature conservation, based on their participation in an environmental education program.

The results of this literature review show that there is a body of work concerning the effects of environmental education programs on knowledge, attitudes, and behaviors. When comparing the number of research findings on adult environmental behaviors it was obvious that research with younger children needed time to develop. The limited findings revealed that additional research is needed because previous studies used outdated models, posed questions to children designed for adults, and measured behaviors children did not have control over to assess children's environmental attitudes, which limited their reliability. It remained clear that in order to develop implementation strategies needed to evaluate the transfer of knowledge into behavior in children, longitudinal studies were needed. 


\section{Section 4: Significant Life Experiences}

Significant life experiences (SLE) research posits that children who have positive experiences in the outdoors early in life generally have increased positive environmental attitudes, beliefs, and values when they reach adulthood. A number of studies, primarily surveys, indicate that positive outdoor experiences during childhood represent the single most important factor in developing a personal concern for the environment (Henniger, 1994; Corcoran, 1999; Palmer, 1993; Tanner, 1980; Wilson, 1997).

The findings from this section suggest that the intrinsic value of the natural environment combined with personal experiences contribute to the attitude, and perceptions children have toward nature. Taken together, these studies seem to indicate that while environmentally oriented adults give credit to their environmental education and training, many acknowledged that time spent in natural places as a child shaped their environmental behavior. Family, friends, and mentors have been identified as playing an active role in creating significant positive outdoor life experiences. SLE research notes that both children and parents must overcome fears and misconceptions about the environment before significant life experiences can be created. This assertion is consistent with results of the constraints literature in Section 1; negotiating these constraints can actually be part of the bonding process. Regardless of the actual effects of interpersonal or institutional constraints, early experiences in nature-based or outdoor activities are considered to be a significant part of reinforcing positive experiences necessary in developing positive environmental attitudes, beliefs and values in children (Romsa and Hoffman 1980; Adams and others, 1986; van Andel 1990). These studies indicate that significant life experiences, whether positive (that is, nurturing, encouraging, and so forth) or negative (that is, fear, dislike, and so forth), seem to develop early in life. Sobel (1996) suggested that providing frequent opportunities for children to become immersed in special outdoor places is one way to support a critical bond with nature and prevent unfounded fears of and prejudices against nature. Wilson (1997) further described these special places as defined, safe, and esthetically pleasing natural environments where children are free to manipulate and explore the natural world as a path toward creating significant life experiences. Another way to support this critical bond with nature is to create environmental communities that give children something to care about (Chawla, 1988 and 1994a).

Other research indicates that when positive outdoor experiences are absent, children tend to develop fears and discomforts that may interfere with learning about the environment (Philipp, 1999; Bixler and Floyd, 1997; Bixler and others, 1994; Adams and others 1986; Hart, 1979; Kaplan, 1977; Simmons, 1994; Wilson, 1994). In his article, "Young Children's Relationship with Nature: Its Importance to Children's Development and the Earth's Future.” White (2004) suggested that a "culture of fear" has parents afraid for their children's safety. Due to "stranger danger," many children are no longer free to roam their neighborhoods or even their own yards unless accompanied by adults (Pyle, 2002). Many working families can't supervise their children after school, giving rise to latchkey children who stay indoors or attend supervised afterschool activities (Louv, 2005). Furthermore, children's lives have become structured and scheduled by adults, who hold the mistaken belief that this organized play will make their children more successful adults (White and Stoecklin 1998). All of these propositions indicate that these constraints decrease the potential for significant positive outdoor experience.

In studies with adults, researchers found that those who look back on their childhood experiences admitted that environmental leaders contributed the most to their environmental attitudes and beliefs, followed by quality time spent in the outdoors with parents, family, 
teachers, and friends (Chawla, 1998; Palmer, 1993; Tanner, 1980; Bixler and others, 2002). Research by Kals and others (1999) went farther to show that frequent and positive place experiences with family and friends in natural areas fosters an emotional affinity and respect for the natural environment.

Wendy Horowitz (1996) interviewed 29 environmental activists and reported that most said their environmental concern developed as a result of direct experiences with nature and that their environmental ethic was tied to family traditions and values. In another study, when Finger (1994) surveyed more than 1,700 Swiss individuals, the results showed that formal education and knowledge about environmental issues was an indicator of the respondent's environmental attitude and behavior. Nearly one-half of these same respondents reported that direct life experience with the natural environment positively affected their environmental behavior. Chawla (1988) found that the most significant life experiences conservationists and natural resource professionals attributed to their environmental attitudes and behaviors occurred during their childhood. In this study of conservation professionals, 91 percent of the respondents cited childhood experiences in the outdoors as the developmental source of their environmental attitudes. In contrast, less than one-half (45 percent) cited their education of natural systems. Similarly, when this same group of respondents was asked to identify the sources of their commitment to environmental protection, 77 percent cited personal experiences in nature, whereas only 38 percent cited their education. In a second study, Chawla (1999) interviewed 50 environmentalists in Norway and found that, in addition to positive experiences in nature during childhood and adolescence, the most frequently mentioned influence was family members who modeled respect for nature. These studies highlight the importance of positive outdoor experiences as significant events in childhood that correlate with attitudes and behavior toward the natural environment.

Wilson (1994) conducted a study with 33 preschool children (ages 3 through 5) that focused on their understandings, attitudes, and feelings regarding the natural environment. The responses were placed in the following categories: fear, dislike, appreciation, caring, enjoyment, and violence. The findings included more expressions of fear, dislike, and violence than of appreciation, caring, and enjoyment. Fear of the environment and wild places were underscored in another study by Simmons (1994). Simmons interviewed a small group of 9-year-olds in a large city. Some of the children in this study expressed fear of big trees and other vegetation (for example, "branches could fall off and hurt you," "a tree might fall down and hurt you," and "there might be itchy weeds"). These same children also expressed fear of animals and bodies of water (for example, "a bird could swoop down and get you," "fish are poisonous and may bite you," "you might fall in the water and drown," "you might fall out of the boat and get eaten by alligators"). These fears by children, coupled with White's (2004) discussion on parents fear for their children (stranger danger), present an indication that fear is a barrier and constraint for both children and their parents.

Wilson (1997) offers the following suggestions on how to help children overcome fears to create positive life experiences.

- Introduce children to the typical natural elements of their own environment (for example, native plants and animals, local waterways, and so forth).

- Avoid overemphasizing the names or labels of natural ecosystems. Focus, instead, on characteristics (for example, how does it look? how does it feel? how does it move? and so forth). 
- Legitimize natural places by telling children why a particular place is special or important, making the importance more real.

- Expand environmental education experiences to places that minimize fears and prejudices against nature.

\section{Summary of Significant Life Experiences on Environmental Behavior}

A developing literature exists which shows that active care for the environment in adulthood is frequently associated with positive experiences of nature in childhood or adolescence, along with childhood role models who give the natural world appreciative attention. However, the literature shows relatively little understanding about the significant life experience directly associated with young children in their current setting. Most research focused on the past experiences and recollection of adults. Researchers found that when looking back on childhood experiences, environmental leaders attributed their environmental behavior to spending time in the outdoors, spending time with parents, family, teachers, or friends, and reading books. These individuals reported that their nature-connectedness typically began in childhood, and that their environmental concern developed as a result of experiences with nature and modeling by influential others. 


\section{Research Needs}

The rationale for this literature review was not as simple as a shortage of published literature concerning children and nature. In fact, there have been a number of publications over the last 10 years that have sought in some way to present and comment upon the research in this area. This review found that there is a shortfall in these various accounts programs designed and maintained by Federal agencies. Through this review, three main areas of future research could be identified. First, there are many information gaps on the processes available to remove constraints to children participating in outdoor activities and programs, not only in established environmental education programs, but in federal agencies developing site specific programs. There are three main areas where additional and up-to-date research is needed:

- Understanding the function and impact of early childhood experiences in the development of environmental attitudes and behaviors. Most of the existing research focused on adult recollections of childhood experiences. Longitudinal studies are needed to find ways to help children better understand, appreciate, and personally connect with the world around them. A common problem experienced when developing children's environmental education programs is approaching education from an adult's rather than a child's perspective. Research is necessary to understand more holistically how children engage and function in natural environments by moving away from working with adult recall and directly working with children. Specifically, few studies were found that attempted to model the effects of recent childhood experience on the development of existing behaviors.

- Evaluating the institutional constraints faced by Federal agencies. Most of the research focused on not-for-profit programs, which typically do not have the same restrictions concerning program development. No studies are available to show the potential institutional constraints faced by Federal agencies. Unfortunately, this review did not find research that provided specific strategies, within managers' powers and jurisdiction, that might alleviate every potential barrier to outdoor recreation participation. Up until now, researchers have focused exclusively on the relationship between demographic characteristics of a population and perceived constraints of those currently using specific recreation services. Additional research is needed on the specific strategies that can be used within the jurisdiction of Federal managers and planners.

- Evaluating best practices used by other programs. The first systematic national examination of outdoor recreation (ORRRC) did not occur until the late 1950s and has never occurred on such a grand scale, since ORRRC's 1962 report "Outdoor Recreation for America" (Betz, 1999). As a major activity, a holistic research approach to outdoor recreation programs, both on a national and local level, has received relatively little consideration. A current evaluation of Federal, State, and local (including not-for-profit) outdoor programs is needed. Most recreation research was directed toward developing specific, and often local, outdoor recreation programs. Though limited in scope, these programs were noteworthy in that they acknowledged improved conditions, solved sitespecific problems, and yielded valuable information at a practical level. However, a systematic evaluation of programs would provide useful information needed to address a broader spectrum of management strategies. The capacity of outdoor recreation programs would be enhanced, because such assessments could provide information that considers current and likely future trends in recreation. 


\section{Conclusions}

Finding ways to connect children with nature is a growing concern for Federal-lands management agencies. However, many of them are not aware of the underpinnings associated with the current and apparent disconnect. The management goals of most public-lands agencies are to serve the current population for the enjoyment of the outdoors while sustaining the resources for future generations. However, if the children are not connected with nature, the achievement of one management goal is likely to impair the achievement of the other. From a managerial point of view, probing the source of leisure constraints may ultimately help in better organizing and promoting leisure activities. Research may be needed to develop focused leisure policies and strategies for every agency providing organized leisure activities

Traditionally, anecdotal evidence was sufficient to demonstrate the benefits of participating in outdoor and environmental programs. For many years, fostering values that bring about knowledge and appreciation of the environment have been the main focus of environmental education programs; however, recent research indicated that there is a need to create long-term attitudinal changes in order to effect an environmental behavioral change in children. The review of literature in this report demonstrated the importance of considering the sociological underpinning of recreation behavior in children. In the past two decades, a substantial change has occurred in how children prefer to spend their leisure time. Children are spending much more of their time indoors, more so than past generations. Their time is spent in front of a computer, television, or video game. Natural outdoor experiences are being replaced by video games and Internet-based knowledge as potential substitutions for firsthand experiences. Levi and Kocher (1999) warned that the risk of using virtual technology-simulated nature experiences that are not a part of children's regular experience-could diminish the value of ordinary, local natural landscapes.

Parental fears about stranger abduction have increased to the point that exploration outside the home is often a forbidden activity. As a result, children's relationship with nature is becoming more mediated and more virtual, to the extent that some children have little to no actual experience with natural settings.

There are two key reasons that called for paying close attention to additional research needs. First, the need to understand generational trends - research that monitors attitudes as markers of long-term social change as today's children will ultimately become leaders with responsibility for environmental stewardship and sustainability. Second, too little is known about the ability or willingness of parents to demonstrate environmental attitudes, beliefs, or values in ways that could influence their children to become environmentally responsible. Finally, because of the absence of comparable longitudinal data across time, there is very little literature on children's environmental attitude and values. Most of the research was descriptive and could not pinpoint attitudinal shifts.

When examining how environmental knowledge and attitudes of children are transferred into pro-environmental behavior, researchers agreed that knowledge and attitudes are parts of the puzzle, but it is a sense of responsibility that translates knowledge into action. An integral part of a child's learning - or of any environmental education program - should be to promote a respect for the environment, teach values related to the environment, and encourage environmentally responsible behavior. Obviously, knowledge acquisition is a crucial beginning, but how a child transfers the knowledge into behavior is ultimately the beginning of becoming an environmentally responsible member of society. The gap between knowledge and behavior is evidenced in the fact that there was limited research available to provide a tentative link needed 
to understand the questions that shape pro-environmental behavior. As a result, the research needed to make this connection is incredibly complex and cannot be synthesized in a single framework or literature review. With that being said, research is needed to provide practical answers to practical questions to understand the relationship between learning (knowledge) and action (pro-environmental behavior).

Well-designed environmental programs that encourage children and influence their environmental knowledge, attitudes, and behaviors have intrigued researchers for more than two decades. A concern with most young children's environmental programs is that the experiences were modeled from the adult's, rather than the child's, perspective. In order to design effective environmental programs, researchers and practitioners should consider developmental models for children's engagement and ways to determine students' knowledge level on environmental issues as well as their attitudes that may ultimately affect their behavior. Early childhood experiences should be nurtured so that as a child's understanding of nature is developed, this early connection could be one that could be carried with them throughout their lives. It has been suggested that early childhood experiences give form to their values, attitudes, and basic orientation toward nature. Regular and positive interactions in nature allow children to feel comfortable in it and become advanced in the development of their environmental attitudes, beliefs, and values. For more than 20 years researchers have recognized that connecting children with nature is key to providing each generation with the tools needed to fostering behaviors needed to improve and protect the environment. This research indicates the need for further investigations to understand the environmental attitudes, behaviors, and knowledge of today's children so that researchers can work to better understand what is needed to connect children with nature and what that connection means to them. 


\section{Definition of Terms}

The following terms are defined as used in the context of this literature review:

Attitudes: A psychological state acquired over a period of time as a result of experiences.

Rokeach (1986) described attitudes as an orientation toward a person, situation, or social process that is held to be indicative of an underlying value or belief.

Children: School-aged children between the ages of 6-14, in grades 1-7.

Constraint: Godbey (1994) defined constraints as barriers that prevent a person from

participating when the person has a desire to undertake some leisure experience. Jackson (1990) stated that constraints are barriers that inhibit one's preference and interest for leisure activities and actual participation.

Environmental Concern: This term is used to refer to the whole range of environmentally related perceptions, emotions, knowledge, attitudes, values, and behaviors.

Intrapersonal Constraint: An internal psychological condition or emotional state that is individually experienced that predisposes a person to define leisure activities as appropriate or inappropriate, interesting or uninteresting, available or unavailable, and so forth (Keane, 1998).

Interpersonal Constraint: Constraints that arise from interaction with other people (for example, friends, family, and others).

Leisure: According to Godbey (1994) leisure could be defined as time, activities, and state of mind. Leisure is time which the individual does not sell for economic gain. In this free time, people can have a number of activities in which the individual may satisfy his/her own free will. Motivations: The internal factors (need, desire, or expectation) that arouse, energize, or activate leisure activities or behaviors.

Nature: The elements of the Earth's environment or wilderness - including geology, forests, oceans, rivers, beaches, the atmosphere, life, and in general, geographic areas that have not been substantially altered by humans, or which persist despite human intervention.

Perception: The way in which individuals process, evaluate, and store information to better interpret and understand their surroundings.

Recreational Activities: Leisure pursuits freely chosen based on interest and intrinsic motivation and usually participated in during one's free time.

Significant Life Experiences: Active participation in events or activities, leading to the accumulation of knowledge or skill.

Structural Constraint: External factors, typically outside people's control, that may interfere with leisure preferences and leisure participation, such as lack of time, transportation, money, or facilities.

Values: Rokeach (1986) also examined values, which he defined as central beliefs about how one should or should not behave. Values develop as a product of learning and experience. 


\section{References Cited}

Adams, C.E., Newgard, L., and Thomas, J.K., 1986, How high school and college students feel about wildlife: Implications for curriculum development: The American Biology Teacher, v. 48, p. 263-267.

Aitken, S.C., 1994, I'd rather watch the movie than read the book: Journal of Geography in Higher Education, v. 18, p. 291-307.

Ajzen, I., and Fishbein, M., 1980, Understanding attitudes and predicting social behavior: Englewood Cliffs, N.J., Prentice-Hall, 278 p.

Allison, M., 1999, Organizational barriers to diversity in the workplace: Journal of Leisure Research, v. 31, p. 78-101.

Allison, M., 2000, Leisure, diversity, and social justice: Journal of Leisure Research, v. 32, p. $2-5$.

Allison, M.T., and Hibbler, D.K., 2004, Organizational barriers to inclusion-Perspectives from the recreation professional: Leisure Sciences, v. 26, p. 261-280.

Arcury, T.A., 1990, Environmental attitude and environmental knowledge: Human Organization, v. 49, p. 300-304.

Arnold, M., and Shinew, K., 1998, The role of gender, race, and income on park use constraints: Journal of Park and Recreation Administration, v. 16, p. 39-56.

Backman, S.J., 1991, An investigation of the relationship between activity loyalty and perceived constraints: Journal of Leisure Research, v. 23, p. 332-344.

Backman, S.J., and Crompton, J.L., 1989, Discriminating between continuers and discontinuers of two public leisure services: Journal of Park and Recreation Administration, v. 7, p. 56-71.

Backman, S.J, and Crompton, J.L., 1990, Differentiating between active and passive discontinuers of two leisure activities: Journal of Leisure Research, v. 22, p. 197-212.

Bassey, M., 2000, Reviews of educational research: Research Intelligence, v. 71, p. 22-29.

Berenguer, J., 2007, The effect of empathy in proenvironmental attitudes and behaviors: Environment and Behavior, v. 39, p. 269-283.

Betz, C.J., 1999, National Outdoor Recreation Assessments: The Free Library, retrieved September 7, 2009, at http://www.thefreelibrary.com/National Outdoor Recreation Assessments.-a053668954.

Bixler, R., Carlisle, D.L., Hammitt, W.E., and Floyd, M.E., 1994, Observed fears and discomforts among urban students on field trips to wildland area: The Journal of Environmental Education, v. 261, p. 24-33.

Bixler, R.D., and Floyd, M.F., 1997, Nature is scary, disgusting and uncomfortable: Environment and Behavior, v. 29, p. 443-467.

Bixler, R.D., Floyd, M.F., and Hammitt, W.E., 2002, Environmental socialization-Quantitative tests of the childhood play hypothesis: Environment and Behavior, v. 34, p. 795-818.

Blake, D.E., 2001, Contextual effects on environmental attitudes and behavior: Environment and Behavior, v. 33, p. 708-725.

Bogner, F.X., 1998, The Influence of short-term outdoor ecology education on long-term variables of environmental perspective: Journal of Environmental Education, v. 29, p. 17-30.

Bowker, J.M., English, D.B.K., Cordell, H.K., 1999, Projections of outdoor recreation participation to 2050: in Cordell, H.K., Betz, C.J., Bowker, J.M., English, D.B.K., Mou, S.H., Bergstrom, J.C., Teasley, R.J., Tarrant, M.A., and Loomis, J., eds., Outdoor recreation in 
American life: A national assessment of demand and supply trends, Champaign, IL: Sagamore Publishing, p. 323-350.

Bradley, J., Waliczek, T., and Zajicek, J., 1999, Relationship between environmental knowledge and environmental attitude of high school students: Journal of Environmental Education, v. 30, p. 17-21.

Brown, P.R., Brown, W.J., Miller, Y.D., and Hansen, V., 2001, Perceived constraints and social support for active leisure among mothers with young children: Leisure Sciences, v. 23, p. 131144.

Bunting, T.E., and Cousins, L.R., 1985, Environmental dispositions among school-age children: Environment and Behavior, v. 17, p. 725-768.

Burdette, H.L., and Whitaker, R.C., 2005, Resurrecting free play in young children: Archives of Pediatric Adolescent Medicine, v. 159, p. 46-50.

Cachelin, A., Paisley, K., and Blanchard, A., 2009, Using the significant life experience framework to Inform program evaluation-The Nature Conservancy's Wings and Water Wetlands Education Program: Journal of Environmental Education, v. 40, p. 2-14.

Cardin, R.J., 1994, A youth perspective on outdoor recreation: The Free Library, retrieved September 8, 2009, at http://www.thefreelibrary.com/A youth perspective on outdoor recreation. (survey)-a015529954.

Carr, D.S., and Williams, D.R., 1993, Understanding the role of ethnicity in outdoor recreation experiences: Journal of Leisure Research, v. 251, p. 22-38.

Centers for Disease Control and Prevention (CDC), 2003, Physical activity levels among children aged 9 to 13 years-United States, 2002, Morbidity and mortality report Weekly, v. 52, no. 33, p. 785-88, retrieved June 4, 2010, at http://www.cdc.gov/mmwr/preview/mmwrhtml/mm5233a1.htm.

Chavez, D.J., 2000, Invite, include, and involve! Racial groups, ethnic groups, and leisure, in Allison, M.T., Schneider, I., eds. Diversity and the recreation profession: State College, PA., Venture Publishing, Inc., p. 179-194.

Chawla, L., 1988, Children's concern for the natural environment: Children's Environments Quarterly, v. 5, p. $13-20$.

Chawla, L., 1994a, Childhood's changing terrain: Incorporating childhood past and present into community evaluation: Childhood, v. 4, p. 221-233.

Chawla, L., 1994b, Alternative paradigms in environmental education research: Children's Environments, v.11, p. 256-260.

Chawla, L., 1998, Significant life experiences revisited-A review of research on sources of environmental sensitivity: The Journal of Environmental Education, v. 29, p. 11-21.

Chawla, L., 1999, Life paths into effective environmental action: Journal of Environmental Education, v. 31, p. 15-26.

Chawla, L., 2002, Spots of time-Manifold ways of being in nature in childhood, in Kahn, P.H., and Kellert, S.R., eds., Children and Nature-Psychological, sociocultural, and evolutionary investigations: Cambridge, Mass., MIT Press, p. 199-225.

Chawla, L., 2006, Research methods to investigate significant life experiences: review and recommendations: Environmental Education Research, v. 12, p. 359-374.

Chawla, L., 2007, Childhood experiences associated with care for the natural world-A theoretical framework for empirical results: Children, Youth, and Environments, v. 17 p. 144-170. 
Chenoweth, R.E., and Gobster, P.H., 1990, The nature and ecology of aesthetic experiences in the landscape: Landscape Journal, v. 9, p. 1-8.

Chick, G., and Doug, E., 2003, Possibility of refining the hierarchical model of leisure constraints through cross-cultural research, in Murdy, J., ed., Proceeding of the 2003 Northeastern Research Symposium, General Technical Report NE-317: Newtown Square, Pa., USDA Forest Service, Northeastern Research Station, p. 338-344.

Clements, R., 2004, An investigation of the status of outdoor play: Contemporary Issues in Early Childhood, v. 5, p. 68-80.

Cohen, S., and Horm-Wingerd, D., 1993, Children and the environment-Ecological awareness among preschool children: Environment and Behavior, v. 251, p. 103-120.

Cohen, S., 1992, Promoting ecological awareness in children: Childhood Education, v. 68, p. 258-260.

Corcoran, P.B., 1999, Formative influences in the lives of environmental educators in the United States: Environmental Education Research, v. 5, p. 207-220.

Courtenay-Hall, P., and Rogers, L., 2002, Gaps in mind-Problems in environmental knowledge-behaviour modeling research: Environmental Education Research, v. 8, p. 283297.

Crawford, D.W., and Godbey, G.C., 1987, Reconceptualizing constraints to family leisure: Leisure Sciences, v. 9, p. 119-127.

Crawford, D.W., Jackson, E., and Godbey, G.C., 1991, A hierarchical model of leisure constraints: Leisure Sciences, v. 13, p. 309-320.

Crompton, J.L., and Kim, S., 2004, Temporal changes in perceived constraints to visiting state parks: Journal of Leisure Research, v. 36, p. 160-180.

Culen, G., and Volk, T., 2000, Effects of an extended case study on environmental behavior and associated variables in seventh- and eighth-grade students: The Journal of Environmental Education, v. 31, p. 9-15.

Dietz, T., Stern, P.C., and Guagnano, G.A., 1998, Social structural and social psychological bases of environmental concern: Environment and Behavior, v. 30, p. 450-471.

Disinger, J., 1982, Environmental education research news: The Environmentalist, v. 2, p.285288.

Dunn, E., 1990, Temporary and permanent constraints on participation in camping: in Smale B.J.A., ed., Leisure challenges: Bringing people, resources, and policy into play, Proceedings of the Sixth Canadian Congress on Leisure Research: Ontario Research Council on Leisure. Toronto, Ontario, p. 360-363.

Dwyer, J.F., and Hutchison, R., 1990, Outdoor recreation participation and preferences by black and white Chicago households, in Vining, J., ed., Social science and natural resource recreation management: Westview Press, Boulder, CO., p. 49-67.

Eagles, P.J., and Demare, R., 1999, Factors Influencing children's environmental attitudes: Journal of Environmental Education, v. 30, p. 33-39.

Engel, S., 1991, The world is a white blanket - Children write about nature: Children's Environments Quarterly, v. 8, p. 42-45.

Evans, G.W., Gernot, B., Aliya, H., Stecker, R., Wong, K., and Shapiro, E., 2007, Young children's environmental attitudes and behaviors: Environment and Behavior, v. 39, p. 635658. 
Evans, G.W., Juen, B., Corral-Verdugo,V., Corraliza, J., and Kaiser, F.G., 2007, Children's cross-cultural environmental attitudes and self-reported behaviors: Children, Youth, and Environments, v. 17 p. 128-143.

Ewert, A., 2002, Research-An essential ingredient in the outdoor recreation mix (ORRRC at 40!): Parks and Recreation, retrieved June 4, 2010, at http://findarticles.com/p/articles/mi_m1145/is_8_37/ai_91398914/?tag=content;col1.

Ewert, A., Place, G., and Sibthorp, J., 2005, Early-life outdoor experiences and an individual's environmental attitudes: Leisure Sciences, v. 27, p. 225-239.

Faber-Taylor, A., and Kuo, F.E., 2006, Is contact with nature important for healthy child development? State of the evidence, in Spencer, C. and Blades, M. eds., Children and their environments: Learning, using and designing spaces, Cambridge University Press, Cambridge, U.K., p. 124-140.

Faber-Taylor, A., Kuo, F.E., and Sullivan, W.C., 2002, Views of nature and self-discipline: Evidence from inner city children: Journal of Environmental Psychology, v. 22, p. 49-63.

Finger, M.F., 1994, From knowledge to action? Exploring the relationships between environmental experiences, learning, and behavior: Journal of Social Issues, v. 50, p. 141-160.

Fishbein, M., and Ajzen, I., 1974, Attitude towards objects as predictors of single and multiple behavioral criteria: Psychological Review, v. 81, p. 59-74.

Fjortoft, I., and Sageie, J., 2000, The natural environment as a playground for childrenLandscape description and analysis of a natural landscape: Landscape and Urban Planning, v. 48, p. 83-97.

Floyd, M.F., 1998, Getting beyond marginality and ethnicity-The challenge for race and ethnic studies in leisure research: Journal of Leisure Research, v. 30, p. 3-22.

Floyd, M.F., 1999, Race, ethnicity and the use of the National Park System: National Park Service Social Science Research Review, v. 1, p. 1-13.

Floyd, M.F., and Gramann, J.H., 1995, Perceptions of discrimination in a recreation context: Journal of Leisure Research, v. 27, p. 192-200.

Floyd, M.F., McGuire, F.A., Shinew, K.J., and Noe, F.P., 1994, Race, class, and leisure activity preferences-Marginality and ethnicity revisited: Journal of Leisure Research, v. 26, p. 158173.

Floyd, M.F., Outley, C.W., Bixler, R.D., and Hammitt, W.E., 1995, Effect of race, environmental preference and negative effect on recreational preferences: Abstracts from the 1995 National Recreation and Park Association Symposium on Leisure Research.

Floyd, M.F., Gramann, J.H., and Saenz, R., 1993, Ethnic factors and the use of public outdoor recreation areas: Leisure Sciences v. 15 p. 83-98.

Foster, A., and Linney, G., 2007, Reconnecting children through outdoor education: A research summary: Council of Outdoor Education of Ontario, Toronto, 79 p.

Francken, D.A., and Van Raiij, M.F., 1981, Satisfaction with leisure time activities: Journal of Leisure Research, v. 13, p. 337-352.

Gaster, S., 1991, Urban children's access to their neighborhood-Changes over three generations: Environment and Behavior, v. 23, p. 70-85.

Gobster, P.H., 1998, Explanations for minority "underparticipation" in outdoor recreation-A look at golf: Journal of Park and Recreation Administration, v. 16, p. 46-64.

Godbey, G., 1985, Non-participation in public leisure services-A model: Journal of Park and Recreation Administration, v. 3, p. 1-13. 
Godbey, G., 1994, Leisure in your life-An exploration: State College, PA., Venture Publishing, Inc., p. 2-6.

Godbey, G., Graefe, A., and James, S., 1992, The benefits of local recreation and park servicesA nationwide study of the perceptions of the American public: Arlington,Va., National Recreation and Park Association, p. 140.

Henniger, M.L., 1994, Adult perceptions of favorite childhood play experiences: Early Child Development and Care, v. 99, p. 23-30.

Hewitt, P., 1997, Games in instruction leading to environmentally responsible behavior: The Journal of Environmental Education, v. 28, p. 35-37.

Hinds, J., and Sparks, P., 2008, Engaging with the natural environment-The role of affective connection and identity: Journal of Environmental Psychology, v. 28, p. 109-120.

Hofferth, S.L., and Curtin, S., 2006, Home media and young children's learning-related activities - Complements or detriments?: Unpublished Research funded by NICHD grant R21-HD-050125, College Park, Md., University of Maryland, 51 p.

Hofferth, S., and Sandberg, J., 2000, Changes in American children's time 1981-1997: Center for the Ethnography of Everyday Life. Retrieved August 27, 2009 at ceel.psc.isr.umich.edu/pubs.

Horowitz, W., 1996, Developmental origins of environmental ethics: The life experiences of activists: Ethics and Behavior, v. 6, p. 29-54.

Howard, D.R., and Crompton, J.L., 1984, Who are the consumers of public park and recreation services? An analysis of the users and non-users of three municipal leisure service organizations: Journal of Park and Recreation Administration, v. 2, p. 33-48.

Howe, R.W., and Disinger, J.F., 1988, Environmental education that makes a differenceKnowledge to behavior changes: ERIC/SMEAC Environmental Education Digest no. 4. Hultsman, W., 1995, Recognizing patterns of leisure constraints-An extension of the exploration of dimensionality: Journal of Leisure Research, v. 27, p. 228-244.

Hungerford, H.R., and Volk, T., 1990, Changing learner behavior through environmental education: Journal of Environmental Education, v. 21, p. 8-21.

Irwin, P.N., Gartner, W.C., and Phelps, C.C., 1990, Mexican American/Anglo cultural differences as recreation style determinants: Leisure Sciences, v. 12, p. 335-348.

Jackson, E.L., 1983, Activity-specific constraints to recreation participation: Leisure Sciences, v. 10, p. 203-215.

Jackson, E.L., 1986, Outdoor recreation participation and attitudes to the environment: Leisure Studies, v. 5, p. 1-23.

Jackson, E.L., 1990, Variations in the desire to begin a leisure activity: Evidence of antecedent constraints?: Journal of Leisure Research, v. 22, p. 55-70.

Jackson, E.L., 1994, Activity-specific constraints on leisure: Journal of Park and Recreation Administration, v. 12, p. 33-49.

Jackson, E.L., 1993, Recognizing patterns of leisure constrains-Results from alternative analyses: Journal of Leisure Research, v. 25, p. 129-149.

Jackson, E.L., Crawford, D.W., and Godbey, G., 1993, Negotiation of leisure constraints: Leisure Sciences, v. 15, p. 1-11.

Jackson, E.L., and Dunn E., 1988, Integrating ceasing participation with other aspects of leisure behavior: Journal of Leisure Research, v. 20, p. 31-45.

Jackson, E.L., and Dunn, E., 1991, Is constrained leisure an internally homogeneous concept?: Leisure Sciences, v. 13, p. 167-184. 
Jackson, E.L., and Scott, D., 1999, Constraints to leisure, in Jackson, E. L., and Burton, T.L., eds.), Leisure studies: Prospects for the twenty-first century: State College, PA: Venture Publishing, p. 299-321.

Jackson, E.L., and Searle, M.S., 1983, Recreation non-participation: Variables related to the desire for new recreational activities: Recreation Research Review, v. 10, p. 5-12.

Jensen, B.B., 2002, Knowledge, action and pro-environmental behavior: Environmental Education Research, v. 8, p. 325-334.

Johnson, C.Y., Bowker, J.M., English, D.B.K., and Worthen, D., 1998, Wildland recreation in the rural south-An examination of marginality and ethnicity theory: Journal of Leisure Research, v. 30, p. 101-121.

Johnson, C.Y., and Bowker, J.M., 1999, On-site wildland activity choices among African Americans and White Americans in the rural south-Implications for management: Journal of Park and Recreation Administration, v. 171, p. 21-39.

Johnson, C.Y., and Bowker, J.M., 2004, African-American wildland memories: Environmental Ethics, v. 26, p. 57-68.

Kahn, P.H., 2002, Children's affiliation with nature-Structure, development, and the problem of environmental generational amnesia, in Kahn, P.H., and Kellert, S.R., eds., Children and nature-Psychological, sociocultural, and evolutionary investigations: Cambridge, Mass., MIT Press, p. 93-116.

Kaiser, F.G., Wolfing, S., and Fuhrer, U., 1999, Environmental attitude and ecological behaviour: Journal of Environmental Psychology, v. 19, p. 1-19.

Kals, E., Schumacher, D., and Montada, L., 1999, Emotional affinity toward nature as a motivational basis to protect nature: Environment and Behavior, v. 31, p. 178-202.

Karsten, L., and van Vliet, W., 2006, Increasing children's freedom of movement -Introduction: Children, Youth and Environments, v.16, p.69-73.

Kaplan, S., 1977, Tranquility and challenge in the natural environment, in Children, nature and the urban environment: USDA Forest Service General Technical Report NE 30. Pp. 181-185.

Kaplan, S., 1995, The restorative benefits of nature: Toward an integrative framework: Journal of Environmental Psychology, v. 15, p. 169-182.

Kay, T., and Jackson G., 1991, Leisure despite constraints - The impact of leisure constraints on leisure participation: Journal of Leisure Research, v. 23, p. 301-313.

Keane, C., 1998, Evaluating the influence of fear of crimes as an environmental mobility restrictor on women's routine activities: Environment and Behavior, v. 30, p. 60-70.

Kellert, S.R. 1976. Perceptions of animals in American society: Trans. North American Wildlife and Natural resources conference, v.41, p. 533-546.

Kellert, S.R., and Westervelt, M.O., 1984, Children's attitudes, knowledge and behaviors toward animals: Children's Environments Quarterly, v. 1, p. 8-11.

Kellert, S.R., 2002, Experiencing nature: Affective, cognitive, and evaluative development in children, in Kahn, P.H., and Kellert, S.R., eds., Children and nature: Psychological, sociocultural, and evolutionary investigations, Cambridge, Mass: MIT., p. 117-152.

Kellert S.R., 2005, Nature and Childhood Development: in Kellert S.R., ed., Building for lifeDesigning and understanding the human-nature connection, Washington, D.C., Island Press, p. 63-89.

Kimbell, A.R., Schuhmann, A., and Brown, H., 2009, More kids in the woods-Reconnecting Americans with nature: Journal of Forestry, v. 107, p. 373-377. 
Kollmus, A., and Agyeman, J., 2002, Mind the Gap: Why do people act environmentally and what are the constraints to pro-environmental behaviour?: Environmental Education Research, v. 8, p. 239-260.

Leeming, F.C., Dwyer, W.O., and Bracken, B.A., 1995, Children's environmental attitude and knowledge scale - Construction and validation: The Journal of Environmental Education, v. 26, p. 22-31.

Levi, D., and Kocher, S., 1999, Virtual nature - The future effects of information technology on our relationship to nature: Environment and Behavior, v. 31, p. 203-226.

Louv, R., 2005, Last child in the woods-Saving our children from nature-deficit disorder: Chapel Hill, N.C., Algonquin Books, p. 334.

Malone, K., and Tranter, P., 2003, Children's environmental learning and the use, design and management of schoolgrounds: Children, Youth, and Environments, v. 13, retrieved September 12, 2009, at http://www.colorado.edu/journals/cye/.

Moore, R.C., 1986, The power of nature orientations of girls and boys toward biotic and abiotic play settings on a reconstructed schoolyard: Children's Environments Quarterly, v. 3, p. 52-69.

Moore, R.C., 1997. The need for nature: A childhood right: Social Justice, v. 2, p. 203-220.

Moore, R., 2004, Countering children's sedentary lifestyles by design: Natural Learning Initiative, retrieved August 22, 2009, at www.naturalearning.org.

Musser, L.M., and Malkus, A.J., 1994, The children's attitudes toward the environment scale: Journal of Environmental Education, v. 25, p. 22-26.

Nabhan, G.P., 1994, A child's sense of wildness, in Nabhan G.P., and Trimble, S., eds., The geography of childhood: Why children need wild places: Boston, Mass: Beacon Press, p. 1-14.

Newhouse, N., 1990, Implications of attitude and behavior research for environmental conservation: The Journal of Environmental Education, v. 221, p. 26-32.

Palmer, J.A., 1993, Development of concern for the environment and formative experiences of educators: Journal of Environmental Education, v. 24, p. 26-30.

Parker, J.D., and McDonough, M.H., 1999, Environmentalism of African Americans-An analysis of the subculture and constraints theories: Environment and Behavior, v. 31, p. 155177.

Penaloza, L.J., 1989, Wisconsin Recreation Survey: Wisconsin Department of Natural Resources, Report No. 167, 24 p.

Phenice, L.A., and Griffore R.J., 2003, Young children and the natural world: Contemporary Issues in Early Childhood, v. 4, p. 137-171.

Philipp, S.F., 1995, Race and leisure constraints: Leisure Sciences, v. 17, p. 109-120.

Philipp, S.F., 1999, Are we welcome? African American racial acceptance in leisure activities and the importance given to children's leisure: Journal of Leisure Research, v. 31, p. 385-403.

Purdy, K.G., and Decker, D.J., 1989, Applying wildlife values information in management: The wildlife attitudes and values scale: The Wildlife Society Bulletin, v. 17, p. 494-500.

Pyle, R., 1993, The thunder trees: Lessons from an urban wildland: Boston: Houghton Mifflin, p.145-148.

Pyle, R., 2002, Eden in a vacant lot-Special places, species and kids in the neighborhood of life_-Children and nature, in Kahn, P.H., and Kellert, S.R., eds., Psychological, sociocultural, and evolutionary investigations: Cambridge, Mass., MIT Press, p. 305-328.

Rideout,V., Vanderwater, E.A., and Waterlla, E.A., 2003, Zero to six; electronic media in the lives of infants, toddlers and preschoolers: Kaiser Family Foundation, retrieved June 4, 2010, at http://www.kff.org/entmedia/entmedia102803pkg.cfm. 
Rideout, S., and Legg, M.H., 2000, Factors limiting minority participating in interpretive programming - A case study: Journal of Interpretation Research, v. 5, p. 53-56.

Rivkin, M., 1990, The Great Outdoors-Restoring children's rights to play outside: National Association for the Education of Young Children, v.108, p. 1-79.

Rokeach, M., 1986, Beliefs, attitudes, and values-A theory of organization and change: San Francisco, Jossey-Bass, p. 124-126.

Romsa, G., and Hoffman, W., 1980, An application on nonparticipation data in recreation research: Testing the opportunity theory: Journal of Leisure Research, v. 12, p. 321-328.

Schroeder, S.A., Fulton, D.C., Nemeth, M.L., Sigurdson, E., and Walsh, R.J., 2008, Fishing in the neighborhood-Understanding motivations and constraints for angling among Minneapolis-St. Paul, Minnesota metro residents: American Fisheries Society Symposium, San Francisco, CA September 3-5, 2007, v. 67, p. 1-19, retrieved January 5, 2011, at http://www.kff.org/entmedia/entmedia102803pkg.cfm.

Schroeder, T.D., and Wiens, M., 1986, The non-use of public park and recreation facilities in Tulsa: Journal of Park and Recreation Administration, v. 4, p. 75-87.

Scott, D., 1991, The problematic nature of participation in contract bridge - A qualitative study of group-related constraints: Leisure Sciences, v. 13, p. 321-336.

Scott, D., 1993, Time scarcity and its implications for leisure behavior and leisure delivery: Journal of Park and Recreation Administration, v. 11, p. 51-60.

Scott, D., 2005, The relevance of constraints research to leisure service delivery, in Jackson E. L., ed., Constraints to Leisure, p. 279-287, State College, PA: Venture Publishing.

Scott, D., and Jackson, E.L., 1996, Factors that limit and strategies that might encourage people's use of public parks: Journal of Park and Recreation Administration, v. 14, p. 1-17.

Scott, D., and Kim, C., 1998, Outdoor recreation participation and barriers to involvement: Report submitted to the Texas Parks and Wildlife Department, retrieved June 23, 2010, at http://www.rpts.tamu.edu/tpwd/scott.pdf.

Scott, D., and Munson, W., 1994, Perceived constraints to park usage among individuals with low incomes: Journal of Park and Recreation Administration, v. 12, p. 52-69.

Scott, D., and Willits, F.K., 1994, Environmental attitudes and behavior: Environment and Behavior, v. 26, p. 239-260.

Searle, M.S., and Jackson, E.L., 1985a., Socioeconomic variations in perceived barriers to recreation participation among would-be participants: Leisure Sciences, v. 7, p. 227-249.

Searle, M.S., and Jackson, E.L., 1985b, Recreation non-participation and barriers to participation: Considerations for the management of recreation delivery systems: Journal of Park and Recreation Administration, v. 3, p.23-36.

Sebba, R., 1991, The landscapes of childhood-The reflection of childhood's environment in adult memories and in children's attitudes: Environment and Behavior, v. 23, p. 395-422.

Shaw, S., Bonen, A., and McCabe, J.F., 1991, Do more constraints mean less leisure? Examining the relationship between constraints and participation: Journal of Leisure Research, v. 3, p. 286-300.

Shinew, K.J., Floyd, M.F., and Parry, D., 2004, Understanding the relationship between race and leisure activities and constraints-Exploring an alternative framework: Leisure Sciences, v. 26, p. 181-199.

Simmons, D.A., 1994, Urban children's preferences for nature-Lessons for environmental education: Children's Environments, v. 11, p. 194-203. 
Simmons, D.A., 1998, Using natural settings for environmental education-Perceived benefits and constraints: Journal of Environmental Education, v. 29, p. 23-31.

Smith-Sebasto, N.J., and Semrau, H.J., 2004, Evaluation of the Environmental Education Program at the New Jersey School of Conservation: The Journal of Environmental Education, v. 36, p. 3-18.

Sobel, D., 1990, A place in the world-Adults memories of childhood's special places:

Children's Environments Quarterly, v. 7, p. 5-12.

Sobel, D., 2008. Children and Nature: Design principles for educators. Portland ME: Stenhouse Publishers, p.184.

Spencer, C., and Woolley, H., 2000, Children and the city: A Summary of recent environmental psychology research: Child Care, Health and Development, v. 26, p. 181-198.

Stankey, G.H., 1997, Institutional constraints and opportunities in application of the limits of acceptable change, in McCool, S.F., and Cole, D.N., compilers: Proceedings from a workshop held at the University of Montana's Lubrecht Experimental Forest, Limits of acceptable change and related planning processes-Progress and future directions: General Technical Report INT-GTR-371, Ogden, Utah, U.S. Department of Agriculture Forest Service, Rocky Mountain Research Station, p. 10-15.

Stodolska, M., 1998, Assimilation and leisure constraints: dynamics of constraints on leisure in immigrant population: Journal of Leisure Research v. 30, p. 521-551.

Tanner, T., 1980, Significant life experiences-A new research area in environmental education: Journal of Environmental Education, v. 11, p. 20-24.

Tanner, T., 1998, Choosing the right subjects in significant life experiences research: Environmental Education Research, v. 4, p. 399-418.

Tarrant, M.A., and Green, G.T., 1999, Outdoor recreation and the predictive validity of environmental attitudes: Leisure Sciences, v. 21, p. 17-30.

Teel, T.L., Dayer, A.A., Manfredo, M.J., and Bright, A.D., 2005, Regional results from the research project entitled Wildlife Values in the West: Project report no. 58 for the Western Association of Fish and Wildlife Agencies: Fort Collins, Colorado State University, Department of Human Dimensions of Natural Resources.

Thapa, B., and Graefe, A., 2003, Forest recreationists and environmentalism: Journal of Park and Recreation Administration, v. 21, p. 77-105.

Thapa, B., Graefe, A.R., and Absher, J.D., 2002, Information needs and search behaviors-A comparative study of ethnic groups in the Angeles and San Bernardino National Forests, California: Leisure Sciences, v. 24, p. 89-107.

Thompson, C.W., Aspinall, P., and Montarzino, A., 2008, The Childhood Factor-Adult visits to green places and the significance of childhood experiences: Environment and Behavior, v. 40, p. 111-143.

Tierney, P.T., Dahl, R.F., Chavez, D.J., 1998, Cultural diversity of Los Angeles County residents using undeveloped natural areas. Res. Pap. PSW-RP-236, Albany, CA: U.S. Department of Agriculture, Forest Service, Pacific Southwest Research Station, p. 76.

Tierney, P.T., Dahl, R., and Chavez, D., 2001, Cultural diversity in use of undeveloped natural areas by Los Angeles county residents: Tourism Management, v. 22, p. 271-277.

Urban, M., and Martin, K., 2008, Developing environmentally responsible behavior-A case study of Trailside Discovery Camp: Camping Magazine, retrieved August 20, 2009, at http://www.acacamps.org/campmag/issues/0807/research.php. 
Valentine, G., and McKendrick J., 1997, Children's outdoor play: exploring parental concerns about children's safety and the changing nature of childhood: Geoforum, v. 28, p. 219-235.

van Andel, J., 1990, Places children like, dislike, and fear: Children's Environments Quarterly, v. 7, p. 24-31.

Vaske, J.J., and Kobrin, K.C., 2001, Place attachment and environmentally responsible behavior: The Journal of Environmental Education, v. 32, p. 16-21.

Walker, G.J., Deng, J., and Dieser, R.B., 2001, Ethnicity, acculturation, self-construal, and motivations for outdoor recreation: Leisure Sciences, v. 23, p. 263-283.

Walker, G.J., and Virden, R.J., 2005, Constraints on outdoor recreation, in Constraints to Leisure, Jackson, E.L., ed.: State College, Pa., Venture Publishing, p. 201-219.

Washburne, R.F., 1978, Black under-participation in wildland recreation-Alternative explanations: Leisure Sciences, v. 1, p. 175-189.

Wells, N.M., and Lekies K.S., 2006, Nature and the life course-Pathways from childhood nature experiences to adult environmentalism: Children, Youth, and Environments, v. 16, p. $1-24$.

Wells, N.M., 2000, At home with nature: effects of "greenness" on children's cognitive functioning: Environment and Behavior, v. 32, p.775-795.

West, P.C., 1989, Urban region parks and black minorities_-Subculture, marginality, and interracial relations in park use in the Detroit metropolitan area: Leisure Sciences, v. 11, p. 11-28.

White, R.A., 2001, Moving from biophobia to biophilia, retrieved August 20, 2009, at www.whitehutchinson.com/children/articles/childrennature.shtml.

White, R., 2004, Young children's relationship with nature-Its importance to children's development and the earth's future, retrieved August 20, 2009, at www.whitehutchinson.com/children/articles/childrennature.shtml.

White, R., and Stoecklin, V., 2008, Nurturing children's biophilia-Developmentally appropriate environmental education for young children, retrieved August 22, 2009, at http://www.whitehutchinson.com/children/articles/nurturing.shtml,

White, R. and Stoecklin, V., 1998, Children's outdoor play and learning environments:

Returning to nature, retrieved August 25, 2009 at www.whitehutchinson.com/children/articles/outdoor.shtml.

Wilson, R., 1997, The wonders of nature-Honoring children's way of knowing: Early Childhood News, v. 6, p. 19.

Wilson, R.A., 1994, Enhancing the outdoor learning environments of preschool programs: Environmental Education, v. 47, p. 11-12.

Witt, P.A., and Goodale, T.L., 1981, The relationship between barriers to leisure enjoyment and family stages: Leisure Sciences, v 4, p.29-49. 


\section{Bibliography}

\section{This bibliography includes full citations and abstracts from the publishing source. While this is a listing of a sample of relevant studies, the listing is not intended to be exhaustive. We welcome recommendations for additional research to include.}

1. Balmford, A., Clegg, L., Coulson, T., and Taylor, J., 2002, Why conservationists should heed Pokémon: Science, v. 295, no. 5564, p. 2367-2367.

In a small, innovative study, Dr. Andrew Balmford and colleagues surveyed 109 United Kingdom (UK) primary schoolchildren (ages 4 to 11) to investigate their knowledge of natural and nonnatural objects. Each child was shown a set of 20 flashcards - 10 of common British wildlife species (including plants, invertebrates, and mammals) and 10 of Pokémon characters. The authors found that while individual children's scores varied, children's overall identification success for common wildlife species rose from 32 percent at age 4 to 53 percent at age 8 and then fell slightly, whereas children's identification success for Pokémon characters rose from 7 percent at age 4 to 78 percent at age 8 . Dr. Balmford and colleagues discuss the possible implications of children's lack of knowledge of common wildlife types and the importance of reconnecting children with local nature.

2. Bixler, R., Carlisle, D.L., Hammitt, W.E., and Floyd, M.E., 1994, Observed fears and discomforts among urban students on field trips to wildland area: The Journal of Environmental Education, v. 26, p. 24-33.

Interpreters at urban nature centers were asked to recall and list fears expressed by students on field trips to wildland areas. Forty-eight interpreters recalled 564 examples of fearful reactions. Responses were interpreted based on the literature on fear. Fears of snakes, insects, nonindigenous animals, and plants were most frequently cited. Enlightening was the high frequency of "fear of getting lost" and the emotion of disgust expressed in relation to natural objects. Results suggest the need to address not only students' fears but also their feelings of disgust. Anxiety reactions from students suggest that interpretive programs for some students may be corrective instead of formative. Of the 60 nature and environmental education centers contacted, we eliminated 3 from the sample because institutional policies required screening of survey instruments by their public relations offices. Three questionnaires sent out as pretests were included in the final sample because no changes were made in the instrument format. Fortyeight surveys were returned after two reminders, for a response rate of 80 percent. Respondents supplied an average of 11 examples of fearful reactions, with a range of 4 to 50. Recorded observations by naturalists provided a broad overview of the many fearful responses made by children. Responses were divided into 23 categories. This research project demonstrates that urban students express a wide range of fearful responses to natural environments. Fear and anxiety pose constraints to enjoying and learning about wildlands. Many interpreters may be spending time correcting misconceptions rather than reinforcing and further developing students' appreciation of nature. Nature centers may best develop accurate perceptions of wildlands by offering outdoor programming for the very young through preschool and day care run by nature centers. Frequent experiences for Head Start children might provide young urban children with positive formative experiences with the out-of-doors before misconceptions are formed. Centers 
may wish to consider "adopting" several urban youth, guaranteeing that at least some urbanites receive regular and lengthy contacts with outdoor environments throughout their childhood and adolescence. Individuals with an accurate perception of nature built from early firsthand experiences are more likely to be "inoculated" against accepting the inaccurate depictions of nature readily available from media, parents, and friends. Regardless of whether learning opportunities have been formative or corrective, this study provides further evidence of the need for urban students to have frequent and direct experiences in wildland environments. The next steps are to evaluate how wildland-related fears and anxieties interfere with learning and then test a wide range of methods for countering fears, disgust, and anxieties related to wildland areas.

3. Bixler, R.D., Floyd, M.E., and Hammitt, W.E., 2002, Environmental socializationQuantitative tests of the childhood play hypothesis: Environment and Behavior, v. 34, p. 795818.

Two studies with adolescent youth $(N=1,376, N=450)$ helped clarify the relationship between childhood play experiences in wild environments and later environmental preferences in the life domains of work, leisure, and school. Respondents who reported playing in wild environments had more positive perceptions of natural environments, outdoor recreation activities, and future indoor/outdoor occupational environments. No significant differences were found for preferences for environmental sciences activities conducted in schools. Results suggested that childhood play in wildland environments is related to environmental competencies and preferences but not necessarily an intellectual interest in environmental sciences or environmentalism.

4. Blake, D.E., 2001, Contextual effects on environmental attitudes and behavior: Environment and Behavior, v. 33, p. 708-725.

Using data from a random sample survey of the population of British Columbia, this article addressed a gap in the literature related to environmental concern and environmental action. The author used a regression model that included contextual effects and measures of political attitudes and environmental knowledge as determinants of individual action in support of environmental action. The analysis showed that there was a significant relationship between environmental concern and the perceptions and behavior related to environmental action. There was a difference of 14.6 percentage points on the individual action scale between those who had the lowest level of concern and those at the highest concern level. The determinants of individual action were not identical to those for collective action. Personal empowerment, based on environmental knowledge and a belief in the efficacy of individual action and postmaterial values were found to be more important for individual than for collective action. On the other hand, personal values, especially environmentalism - the extent of acceptance of the major tenets of the environmentalist creed - contributed more to explaining endorsement of collective action. This analysis also provides further evidence of the importance of distinguishing among types of environmental action when analyzing public opinion on the environment.

5. Bogner, F.X., 1998, The influence of short-term outdoor ecology education on long-term variables of environmental perspective: Journal of Environmental Education, v. 29, p. 17-30. 
The objective of this study was to evaluate the ultimate goals of environmental and ecological education: fostering responsible environmental behavior, effecting long-term changes of students' attitudes toward conservation and nature, and providing basic ecological knowledge. One-day and 5-day versions of a long-established outdoor ecology program in a national park were examined. The study was designed as a pre- and post-treatment evaluation, and the post-test was delayed for 1 month after participants experienced the outdoor education program (post-test was delayed for 6 months with a subsample). Approximately 700 students were surveyed by means of multiple-choice knowledge statements; the survey showed that both programs fostered cognitive levels. Similarly, the scores within the subdivision Human-Altered Nature increased. Furthermore, the 5-day program explicitly provoked favorable shifts in individual behavior, both actual and intended, a parameter that is generally seen as a complex and long-term process. Comparison of the average pupil population with the population enrolled in the outdoor education programs surprisingly revealed a more proenvironmental orientation in students enrolled in the program before any education at the nature site took place. Possible reasons - preselection and(or) presensitizing of students - are discussed.

6. Cachelin, A., Paisley, K., and Blanchard, A., 2009, Using the Significant Life Experience framework to inform program evaluation-The Nature Conservancy's Wings and Water Wetlands Education Program: Journal of Environmental Education, v. 40, p. 2-14.

The purpose of this study was to assess the value of techniques used with SLE research. The authors piloted a mixed-methods evaluation, measuring both cognitive and affective responses to a field education program (the Wings and Water Program). Participants were four groups of fourth-grade students: two attended an environmental field program (treatment groups: $n 1=24$ and $n 2=25$, for a total of 49 students); and two of which did not attend the program (comparison groups: $n 3=24$ and $n 4=26$, for a total of 50 students). The survey results suggested that fieldbased participants demonstrated greater cognitive understanding than classroom-based participants. Qualitative responses suggested that field programs fostered different affective reactions than did classroom programs. These results have critical implications for field-based programming, classroom instruction, and evaluation.

7. Carr, D.S., and Williams, D.R., 1993, Understanding the role of ethnicity in outdoor recreation experiences: Journal of Leisure Research, v. 251 p. 22-38.

This study looked at the variability of outdoor recreation experiences among Hispanic visitors in California parks. Hispanic visitors were given onsite questionnaires to determine if ancestral group membership (Mexican compared to Central American), generational status (immigrant, first generation, second generation), and acculturation (acceptance of dominant culture) influence recreation patterns and reasons for recreating. They found that visitors tended to recreate with similar others. This meant that immigrants tended to group together. Those with higher levels of acculturation were the most likely to be at a site with a large Anglo population since they were more similar to this group. Regardless of ancestry, spending time with family seems to be a major driving force for recreation. There was also a subset of Central American ancestry for whom the outing held religious meaning (baptism, and so forth). Finally, those who are less acculturated to the United States had different norms for recreation in the forest. These findings emphasize the importance of not oversimplifying cultural categories. 
8. Chawla, L., 1998, Significant life experiences revisited-A review of research on sources of environmental sensitivity: The Journal of Environmental Education, v. 29, p. 11-21.

In this article, Chawla argued that environmental behaviors and attitudes can be improved using empathic perspective-taking for inducing empathy. Based on Batson's Model of Altruism, the author predicted that higher levels of empathy would improve environmental attitudes and behaviors. It was also predicted that a causal model could be established between empathy and environmental attitudes and behaviors. This study reported on the relationship between high or low empathy levels, environmental attitudes, and behaviors. The results of this study indicated that participants who showed a high empathy level displayed stronger environmental behaviors and attitudes. Additional analysis showed the effects of evoked empathy for a natural object (bird or tree) on the willingness to act in a way that protects the environment (attitudes and behaviors).

9. Clements, R., 2004, An investigation of the state of outdoor play: Contemporary Issues in Early Childhood, v. 5, p. 68-80.

In this study, Dr. Rhonda Clements surveyed more than 800 mothers in the United States to explore the extent to which children in the early 2000s play outdoors as compared to a generation ago when the mothers interviewed were children. In analyzing the survey results, Dr. Clements found that children in the early 2000 s, as compared to a generation ago:

- $\quad$ spend less time playing outdoors;

- participate in different activities outdoors (for example, fewer street games and more organized youth sports); and

- participate in more indoor than outdoor play activities.

In her survey, Dr. Clements also asked mothers about obstacles to outdoor play and their thoughts regarding the benefits of outdoor play. She found that while almost all mothers recognized some of the diverse benefits of outdoor play, obstacles, such as television, computers, and concerns about crime, safety, and injury, prevented their children from participating in more outdoor play. This study provides important insights into the changing nature of children's outdoor play and is one of the few studies that explore this topic in the United States.

10. Engel, S., 1991, The world is a white blanket - Children write about nature: Children's Environments Quarterly, v. 8, p. 42-45.

In a study of sixth-grade students, it was found that ecologistic and moralistic attitudes toward the environment correlated with talking about the environment at home, watching nature films, and reading about the environment. There were no gender differences in ecologistic attitude, but girls showed higher moralistic attitude scores. Engle reported that a week-long outdoor education program at a residential camp did not produce any measurable differences in ecologistic or moralistic attitudes. The results suggested that the students who entered the camp program with moderate levels of ecologistic and moralistic attitudes derived them from several influences: family, media, and previous school-based environmental education programs. The findings suggested that long-term media and family influences created an environmental attitude profile that was similar to one that was desired by planners of outdoor education program. Engel surmised that it was not surprising that the week-long camp program did not increase existing 
ecologistic and moralistic attitudes. He also suggested that the program did not need to focus on its attitude-modifying goals; however, it would be reasonable for the program to concentrate on building factual and cognitive structures upon the current environmentally positive attitudes of the children.

11. Evans, G.W., Gernot, B., Aliya, H., Stecker, R.,Wong, K., and Shapiro, E., 2007, Young children's environmental attitudes and behaviors: Environment and Behavior, v. 39, p. 635658.

The article presented the results of a study that assessed first- and second-grade children's $(\mathrm{N}=100, \mathrm{M}=6.8$ years) environmental attitudes and behaviors. A series of games derived primarily from dimensions of the new ecological paradigm theory of environmental attitudes is described for the assessment of environmental attitudes. The games included felt board construction, a board game, and an adjustable worry thermometer. Environmental behaviors were assessed in the same sample by using magnitude estimation (jumping different distances to indicate frequency of engagement in behavior) based on an adoption of Kaiser's General Environmental Behavior Scale for adults. The behavior scale used a Rasch measurement model because the authors felt that environmental behaviors were viewed as a consequence of attitudes in concert with difficulties to implement actions.

12. Evans, G.W., Juen, B., Corral-Verdugo, V., Corraliza, J., and Kaiser, F.G., 2007, Children's cross-cultural environmental attitudes and self-reported behaviors: Children, Youth and Environments, v. 17, p. 128-143.

This study explored possible cross-cultural differences in environmental attitudes and self-reported behaviors among young elementary school children in the United States, Austria, Mexico, and Spain. Middle-class children between the ages of 6 and 8 were sampled in rural areas and small cities/towns in the United States $(n=100)$, Austria $(n=41)$, Mexico $(n=126)$, and Spain $(n=25)$. Half of the children were female, and the mean ages of children in the four countries ranged from 6.7 years to 7.4 years. Three interactive games were used to assess children's environmental attitudes, and one game was used to measure self-reported environmental behaviors. One of the three attitudinal games consisted of a board game where the child moved a figure around the board by throwing dice, and at various junctures the child had to choose between two options he or she would prefer (for exaple, play outside or watch television inside). Another attitudinal game used a "worry thermometer" depicting three faces that indicated either "no worry," "some worry," or "a lot of worry." The child moved the thermometer to indicate his or her degree of concern about various local environmental problems and issues (for example, toxic waste from a landfill encroaching upon a neighborhood). Environmental behaviors were self-reported and assessed with a jumping game. The child jumped to a designated line on the floor to indicate how frequently (Never, Sometimes, Most of the Time) he or she engaged in a particular behavior (for example, walking in nearby nature with a parent). They found only one clear cross-cultural difference. U.S. children compared to their counterparts in the three other countries seemed to have lower environmental attitudes. This did not translate into fewer proecological behaviors. 
13. Ewert, A., Place, G., and Sibthorp, J., 2005, Early-life outdoor experiences and an individual's environmental attitudes: Leisure Sciences, v. 27, p. 225-239.

This study investigated the effects of early-life experiences on an individual's environmental beliefs. The researchers used a modified NEP (New Environmental Paradigm) scale to determine the degree to which current environmental beliefs could be explained by early childhood experiences. Data from a survey of 533 university undergraduate students from 20 areas of academic study were analyzed. Six questions focused on ecocentric attitudes, and six questions focused on anthropocentric attitudes toward the environment and 18 types of early-life outdoor experiences. These included a recollection of early-life events, involvement in early-life organizations, organizational camping, family outdoor experiences, political viewpoints, appreciative experiences (alone, with family, and with friends), consumptive experiences (alone, with family, and with friends), their mechanized experiences (alone, with family, and with friends), the influence of negative experiences (for example, pollution, loss of favorite place, and so forth), the influence of media, the influence of teachers and adults, and the influence of earlylife environmental education. Results showed that four of the seven independent variables (appreciative outdoor activities, consumptive outdoor activities, media exposure, and witnessing negative environmental events) explained 14 percent of the variance in the ecocentric/anthropocentric beliefs. Three of the independent variables (early-life participation in mechanized outdoor activities, education, and involvement with organizations) were not significant predictors of ecocentric/anthropocentric beliefs. Implications for research and practice were discussed.

14. Ewert, A.W., 1993, Research in land ethics - The problem of ethnicity, culture, and methods, in Ewert, A.W., Chavez, D.J., and Magill, A.W., eds., Culture, conflict, and communication in the wildland-urban interface: San Francisco, Calif., Westview Press, p. 299-312).

The author presented several different concepts related to culture and natural areas. First, he discussed the land ethic. He provided the argument that land ethic is the morality- and valueladen feelings associated with natural areas. Many of the factors that influence land ethic, such as norms and beliefs, can be influenced in turn by a person's culture. Second, he warned of the danger of stereotyping people when you generalize information about different cultures. Finally, he covers some of the basics of assimilation and acculturation, adapting to the prominent culture.

15. Floyd, M.F., 1999, Race, ethnicity and the use of the National Park System: National Park System Social Science Research Review, v. 1, p. 1-13.

Floyd provided an overview of four major theories used to explain recreation participation by minority groups (marginality hypothesis, ethnicity hypothesis, assimilation theory, and discrimination theory. This article is often cited because it offers a great literature review that includes sources on all kinds of groups and recreation areas. He reviewed the most up-to-date research methods used, which may give the reader some ideas on how to approach future research. He concluded by highlighting the areas that required additional more research.

16. Floyd, M.F., and Gramann, J.H., 1995, Perceptions of discrimination in a recreation context: Journal of Leisure Research, v. 27, p. 192-200. 
These researchers looked at how level of acculturation (acceptance of the dominant culture) influenced perceptions of discrimination in recreation among Mexican Americans. They found that Mexican Americans who were more acculturated perceived less discrimination in recreation settings. The discrimination hypothesis, examined in studies such as Gramman (1996) and Floyd and others (1993), examines how both perceived and actual discrimination affect participation.

17. Floyd, M.F., McGuire, F.A., Shinew, K.J., and Noe, F.P., 1994, Race, class, and leisure activity preferences-Marginality and ethnicity revisited: Journal of Leisure Research, v. 26, p. $158-173$.

This study examined the possible reasons why African-American participation rates outdoor recreation activities were lower than whites. The authors reviewed the marginality and the ethnicity hypotheses. The marginality hypothesis "suggested blacks do not participate because of poverty and various consequences of socioeconomic discrimination, and the ethnicity hypothesis holds that recreation patterns of African-Americans are based on subcultural differences in the values, beliefs, norms. The researchers found that, though a few particular activities varied with perceived class or ethnicity, it seems that both hypotheses contribute to explaining leisure preferences. The also suggested that cultural processes were more useful in explaining variation between blacks and whites in leisure participation. From their research, they found that blacks exhibit higher involvement in team sports, fitness activities, socializing, and participating in volunteer organizations and less involvement in outdoor activities such as camping and hiking. On the other hand, whites preferred walking and outdoor activities such as hunting.

18. Gaster, S., 1991, Urban children's access to their neighborhood-Changes over three generations: Environment and Behavior, v. 23, p. 70-85.

In this small, innovative study, Dr. Sanford Gaster interviewed 29 long-time residents in one New York City neighborhood to understand how children's use of their neighborhood changed between 1915 and 1976. He also analyzed U.S. Census data to understand demographic changes that occurred during this time period. While the small sample size prevented statistical analyses of the data, Dr. Gaster analyzed the content of the interviews, as well as the census data, to understand changes in the physical, social, and economic landscape. With this information, he made intergenerational comparisons. Some of his key findings are listed here:

- The age at which children were allowed outside unsupervised increased over time.

- Children visited more places in their neighborhood when the outdoor opportunities were the most diverse and numerous.

- The number of constraints to children's outdoor exploration has increased over time, and the types of constraints have shifted from being more environmental (for example, a river) to being more social.

- The availability and level of participation in professionally supervised activities increased significantly over time.

- Even within the same neighborhood, children's experiences may differ due to racial and economic differences. Dr. Gaster's study highlights the multitude of forces that have 
likely shaped children's access to their neighborhood and provides important insights to present-day issues and questions.

19. Gobster, P.H., 2002, Managing urban parks for a racially and ethnically diverse clientele: Leisure Sciences, v. 24, p. 143-159.

Onsite surveys in Lincoln Park in Chicago found that there were similarities and differences among visitors from different ethnic groups. For example, activities like walking, swimming, sunning, picnicking, barbecuing, going to the zoo, relaxing, and bicycling were popular with people from all ethnic groups. However, minority group members were more likely to prefer social, passive activities than white visitors. Furthermore, while white respondents were twice as likely to view the park as unsafe, 1 in 10 minority group members reported incidents of discrimination (14 percent of black respondents, 9 percent of Asian respondents, and 7 percent of Latino respondents). Another important finding of the study was that there is variation within ethnic groups as well—something always important to remember.

20. Hinds, J., and Sparks, P., 2008, Engaging with the natural environment-The role of wive connection and identity: Journal of Environmental Psychology, v. 28, p. 109-120.

This study investigated the utility of an extended model of the theory of planned behavior (TPB). It was hypothesized that both affective connection and identification with the natural environment would contribute significantly to the prediction of people's intentions. A secondary hypothesis was that participants who had grown up in rural areas would report more positive orientation toward engaging with the natural environment than would urban participants. The research found that affective connection was a significant, independent predictor of intentions to engage with the natural environment. Environmental identity was only a significant predictor in the absence of affective connection in the regression model. As predicted, rural and urban participants differed significantly along the measured variables.

21. Johnson, C.Y., and Bowker, J.M., 1999, On-site wildland activity choices among AfricanAmericans and White Americans in the rural south-Implications for management: Journal of Park and Recreation Administration, v. 17, p. 21-39.

This self-reporting survey focused on the different activity choices of white and AfricanAmerican visitors to Apalachicola National Forest. The authors divided the activities into the categories of consumptive, those that have some extent of harvesting the land (fishing, gathering berries), compared to nonconsumptive, those that do not take from the land (camping, picnicking). They found that activity participation for white and African-American visitors was similar for the consumptive activities, but African-Americans participated less in nonconsumptive activities. Though the cause for this difference is as yet unknown, the authors postulate that subsistence needs may have a part to play in the results.

22. Johnson, C.Y., and Bowker, J.M., 2004, African-American wildland memories: Environmental Ethics, v. 26, p. 57-68. 
This article looked at the way memories passed down through culture (collective memories) shaped perceptions of wilderness. Because the greatest gaps in perceptions about nature between white and African-Americans centers on perceptions of wilderness, the authors looked at the historical associations African-Americans have with wilderness. By looking at three different periods in history, the authors show how African-Americans may have different perceptions of nature and wilderness. Below is a brief synopsis of their findings:

- 1820-1913: Preenvironmental Movement

To exert more control on slaves, their white masters would tell horror stories of the wilderness. For those who work the land, like many slaves did, nature tends to be less romanticized. The third-largest slave industry was the extraction of turpentine from pine forests, grueling and dangerous work in remote wilderness areas.

- 1914-1959: Early Environmental Movement

Turpentine extraction continued to flourish and depended on the work of AfricanAmericans, or "Turpentine Negros. Because a higher proportion of lynchings occurred in more isolated, "natural" areas, these types of areas embodied the fear of lynchings.

- 1960-present: Modern Environmental Movement

The beginning of the environmental justice movement. This movement began with the realization that environmental hazards were disproportionately being thrust upon people of color. This began an activist movement to improve environmental conditions and expose the racism inherent in the current distribution of environmental hazards.

23. Johnson, C.Y., Bowker, J.M., and Cordell, H.K., 2004, Ethnic variation in environmental belief and behavior-An examination of the New Ecological Paradigm in a social psychological context: Environment and Behavior, v. 36, p. 157-186.

This evaluation is based on data from the 2000 National Survey on Recreation and Environment (NSRE). The original data came from random-digit-dial phone survey. Utilizing questions based upon the New Ecological Paradigm (NEP) (a way to measure environmental beliefs) and ethnicity results, the authors found that, while some behaviors were not moderated by environmental beliefs, African-Americans and foreign-born Latinos tended to have lower scores on the NEP. Asian Americans and U.S.-born Latinos had similar belief systems to the white respondents. The authors also examined four environmental behaviors, with mixed results and the possibility of measurement error. The take-home message is that the way we measure environmental beliefs seems to be biased toward the dominant culture.

24. Johnson, C.Y., Bowker, J.M., English, D.B.K., and Worthen, D., 1998, Wildland recreation in the rural south-An examination of marginality and ethnicity theory: Journal of Leisure Research, v. 30, p. 101-121.

This study used surveys of residents near the Apalachicola National Forest to examine visitation differences between respondents who were white and African-American. The researchers were testing the marginality and ethnicity hypotheses (marginality hypothesishistorical discrimination has led to less participation by the nondominant groups; ethnicity 
hypothesis - members of different cultural groups tend to prefer different recreation activities). They found that African-Americans were less likely to visit, but neither the marginality nor ethnicity hypotheses could fully explain this behavior. They worked better in combination than individually.

25. Kahn, P.H., 2002, Children's affiliation with nature-Structure, development, and the problem of environmental generational amnesia, in Kahn, P.H., and Kellert S.R., eds., Children and nature - Psychological, sociocultural, and evolutionary investigations: Cambridge, Mass., MIT Press: p. 93-116.

The contribution to this volume incorporated research from cognitive science, developmental psychology, ecology, education, environmental studies, evolutionary psychology, political science, primatology, psychiatry, and social psychology. In the 12 individually authored chapters, contributors examine the evolutionary significance of nature during childhood; the formation of children's conceptions, values and sympathies toward the natural world; the effect of nature on children's physical and mental development; and the educational and political consequences of the weakened childhood experience of nature in modern society.

26. Kals, E., Schumacher, D., and Montada, L., 1999, Emotional affinity toward nature as a motivational basis to protect nature: Environment and Behavior, v. 31, p. 178-202.

This article focused on the role of emotions and, more specifically, on emotional affinity toward nature for explaining nature-protective behavior. As an overall result, the power of emotional affinity toward nature to explain nature-protective behavior is confirmed. A questionnaire was used to gather the data for this study. The focus was on emotional motivations to protect nature, using the emotional affinity toward nature model. Multiple regression analyses reveal that (1) emotional affinity is as powerful to predict nature-protective behavior as indignation and interest in nature and together these three predictors explain as much as 47 percent of variance of the criterion variables, and (2) 39 percent of emotional affinity toward nature traces back to present and past experiences in natural environments. The results lead to the following theoretical conclusions: All main predictors (emotional affinity, interest, indignation, and experiences with nature) that were considered within this article should be considered in models for explaining behaviors to protect nature. Nature-protective behavior cannot be sufficiently explained using a pure rational/cognitive approach.

27. Kollmuss, A., and Agyeman, J., 2002, Mind the gap-Why do people act environmentally and what are the constraints to pro-environmental behavior?: Environmental Education Research, v. 8, p. 239-260.

Kollmuss and Agyeman argued that a number of theoretical frameworks have been developed to explain the gap between the possession of environmental knowledge and environmental awareness, and proenvironmental behavior. Although many hundreds of studies have been undertaken, no definitive explanation has yet been found. This article described three of the most influential and commonly used analytical frameworks: (1) early U.S. linear progression models; (2) altruism, empathy and prosocial behavior models; and (3), sociological models. All of the models discussed indicated that the question of what shapes pro- 
environmental behavior is complex and cannot be visualized through one single framework or diagram. The authors analyzed factors that influence (positive or negative) proenvironmental behavior. The factors included demographic, external (for example, institutional, economic, social and cultural), and internal (for example, motivation, proenvironmental knowledge, awareness, values, attitudes, emotion, locus of control, responsibilities and priorities). The authors concluded by suggesting that the development of a single model that incorporates the all of the factors contributing to proenvironmental behavior might neither be feasible nor useful, but they felt it would help illuminate this complex field.

28. Lewis, S., and James, K., 1995, Whose voice sets the agenda for environmental education? Misconceptions inhibiting racial and cultural diversity: Journal of Environmental Education, v. 26, p. 5-13.

For those who have environmental education programs in their facilities, this article focuses on misconceptions that can hinder diversity as well as some practical tips for increasing diversity. The misconceptions are listed:

- People of color are not interested in environmental issues.

- People of color have not been involved in environmental issues so there are not enough role models.

- The issues we look at in environmental education programs and the way they are presented appeal to people from all cultures.

- People of color do not want careers in environmental education.

- The needs of people of color are being addressed in environmental education programs.

To make improvements, the authors suggested: learning about what the audience's interests are, collaborating with members of diverse cultural groups, recognizing where diversity is already present, and avoiding stereotype that marginalize members of the nondominant culture.

29. Louv, R., 2005, Last child in the woods-Saving our children from nature-deficit disorder: Chapel Hill, North Carolina, Algonquin Books, p. 334.

In his book, "Last Child in the Woods," Richard Louv promotes a condition he refers to as "nature-deficit disorder." He makes the case that today's children are truly estranged from the natural environment and that this separation carries long-lasting consequences. Teachers, counselors, and other youth workers have found this book to be a valuable resource. According to Louv, while close contact with nature clearly benefits children, the lack of such connections produces negative consequences. This book highlights conversations with parents, children, teachers, scientists, religious leaders, child-development researchers, and environmentalists. Each conversation offered a unique perspective regarding nature deficit and its effects. Louv speculated that because of the environment-child rift, many citizens may not develop a sense of environmental stewardship. Louv stresses the difference between observing (using computers, hand-held gizmos, television) and acting (walking through a fragrant meadow, damming a stream, or catching and intently examining a toad). Louv concluded by acknowledging that 
sending children outside to play has become increasingly difficult. He suggested that this stems from three causes:

- competition from indoor pastimes,

- adult fears that children will meet with threats to their safety, and,

- a rigid environmentalism that occasionally promotes a hands-off attitude toward nature.

30. Palmer, J.A., 1993, Development of concern for the environment and formative experiences of educators: Journal of Environmental Education, v. 24, p. 26-30.

This study examined the importance of formative life experiences on the development of environmental educators' knowledge of and concern for the environment. The motivation for this study was the belief that if a fundamental aim of education is to help students understand and appreciate the environment, then those responsible teaching them should know the types of learning experience needed to develop active and informed minds.

The author surveyed environmental educators in the United Kingdom. In this sample, there were 232 responses: 102 from male subjects and 130 from female subjects. Of the respondents, 55 were in the under-30 age group, 124 in the 30-50-year age group, and 53 in the over 50-year group. The respondents were asked to provide details of their age group, gender, and demonstration of practical concern for the environment. They were then asked to write an autobiographical statement identifying the formative experiences and influences that led to their concern about the environment. The researchers also asked them to state what events they considered to be their most significant and memorable life experiences in the development of positive attitudes toward the environment. The researchers acknowledged that the aim of the study was to confirm the sample as a group of active and informed citizens; that is, those who knew and cared about the environment in their adult life (they did this by asking respondents to give details of an activity showing their practical concern for the environment).

31. Parker, J.D., and McDonough, M.H., 1999, Environmentalism of African Americans-An analysis of the subculture and constraints theories: Environment and Behavior, v. 31, p. 155177.

The authors were critical that questions of environmentalism among African-Americans other ethnic minorities continued to exist when there was a proliferation studies of environmental behaviors of nonminorities. This study examined the effectiveness of the subculture and constraints theories. The authors were most interested in (1) assessing the differences between African-Americans' and Euro-Americans' environmental attitudes, (2) determining preferences for, and frequency of participation in environmental behaviors of African-Americans and EuroAmericans, and (3) testing the feelings of powerlessness as constraints to environmental behavior. Both-African Americans and Euro-Americans showed environmental concern in their attitudes and reported participating occasionally to frequently in environmentally responsible behaviors. The relationship of powerlessness to environmental behavior was stronger for African-Americans than Euro-Americans. This study challenged earlier works that suggested African-Americans showed little concern about the environment and gave limited support to the theory that explained feelings of powerlessness which create a barrier to positive environmental behavior or participation. The results of this study provided information needed to understand of the relationship between ethnicity and environmentalism. The authors concluded by stating that a 
better understanding of environmentalism of people of all ethnic backgrounds is necessary if the environmental movement is to go forward, if resources are to be managed adequately, and if environmental legislation is to be designed to aid all Americans.

\section{Penaloza, L.J., 1989, Wisconsin Recreation Survey: Wisconsin Department of Natural}

Resources Report no. 167, 24 p.

Penaloza reported the results of a survey designed to measure attitudinal and behavioral differences between Wisconsin residents who used State Parks for outdoor recreation and those who did not. In August 1986 the survey was mailed to 1,373 randomly selected Wisconsin residents. The response rate was 76 percent ( 65 percent were nonusers and 35 percent were users of State Parks). The results indicated that nonusers had less time and were less interested in most recreational activities. Lack of time, lack of interest, and lack of information were all cited as primary constraints to the use of State Parks. Childhood experiences were noted as significant factors that influenced adult's recreation choices. The study concluded that information dissemination was the most effective method for encouraging nonusers to regularly use State Parks and for socializing children toward outdoor recreation experiences.

33. Pergams, O.R.W., and Zaradic, P.A., 2006, Is love of nature in the US becoming love of electronic media? 16-year downtrend in National Park visits explained by watching movies, playing video games, Internet use, and oil prices: Journal of Environmental Management, v. 80, p. 387-393.

Since 1988, per capita visits to U.S. National Parks have declined by about 20 percent. In this study, Drs. Oliver Pergams and Patricia Zardic investigated some potential reasons for this decline. While there are many possible contributing factors, they focused on those related to how Americans spend their time and, specifically, time associated with electronic entertainment media (for example, hours of television, video games, home movies, and Internet use). Drs. Pergams and Zardic note that since 1988 there has been a substantial shift in Americans' use of time. For example, in 2003 the average person spent 327 more hours per year with entertainment media than in 1987. This shift in time clearly affects time devoted to other activities, one activity of which could be National Park visits. In their analysis, Pergrams and Zardic found that a number of entertainment media variables, as well as inflation-adjusted oil prices, appeared to explain almost all of the decline in National Park visits. While this study only looked at association between factors, and not causation, it is an important first step in beginning to understand why U.S. National Park attendance has declined and is continuing to decline and what this might mean for children's exposure to nature.

34. Scott, D., 2004, Trends in outdoor recreation and nature tourism-Implications for south Texas and northern Mexico. Available at http://cnrit.tamu.edu/cgrm/whatzhot/monterrey/scott.html.

The author of this paper reported that nature tourism is neither a panacea nor a quick fix in solving community economic problems. This commentary identified different societal and demographic factors that influenced people's participation in outdoor recreation and nature tourism; the commentary examined trends in outdoor recreation participation in the United States 
and Texas, and it explored the diversity participants. The author examined various societal and demographic factors that are likely to influence people's participation in outdoor recreation and nature tourism activities, such as population changes, aging of population, increase in the number of minorities, changes in family structure, changes in technology, stable work week, growing sense of time scarcity, and increased diversity in the meaning of outdoor recreation. Among the series of U.S. Government studies conducted to monitor trends in outdoor recreation, the most recent is the 1994-95 National Survey on Recreation and the Environment (NSRE).

35. Scott, D., 1993, Time scarcity and its implications for leisure behavior and leisure delivery: Journal of Park and Recreation Administration, v. 11, p. 51-60.

The article is a commentary on direct effects of time scarcity on recreational behavior. When confronted with issues surrounding the issue of time scarcity, the author suggested that people tend to seek to maximize their leisure time by engaging in goods-intensive behavior, pursuing activities simultaneously or more quickly, using time more precisely, and becoming more self-directed in behavior. The author is critical that leisure organizations have been slower in responding to time scarcity than issues such as deteriorating infrastructure and growing cultural diversity. He offered suggestions that included general methods that could be used to respond to people's need to save time. The primary suggestion was for organizations to provide complete information about time requirements.

36. Shinew, K.J., Floyd, M.F., and Parry, D., 2004, Understanding the relationship between race and leisure activities and constraints-Exploring an alternative framework: Leisure Sciences, v. 26, p. 181-199.

Because so much research on race/ethnicity/culture and recreation focuses on the marginality and ethnicity hypotheses, these researchers chose to explore another framework. They used a gender framework by Shaw and others (1991) to study African-American and Caucasian park visitors in Chicago. Consistent with previous research, the two ethnic groups had different leisure activity preferences. What did not match expectations was that AfricanAmerican users answered that they perceived fewer constraints than white park users. This was different than in previous studies, illustrating that is important to learn about your specific site as it may be different from other sites. The researchers also noticed that even in the racially mixed parks, the races were self-segregating and not interacting much with visitors of other races.

37. Simmons, D.A., 1994, Urban children's preferences for nature-Lessons for environmental education: Children's Environments, v. 11, p. 28-40, retrieved September 1, 2009, at http://www.colorado.edu/journals/cye/.

The author opened this article with the premise that a part of a child's environmental education experiences may well involve spending time in a natural environment. But she went farther to speculate that too little is known about how children perceive nature. The focus of this study was to determine urban students' preferences for the natural environment. The goal was to describe how urban children viewed natural settings, what interested them the most, how they differentiated environments, and what seemed to worry them most about visiting nature. Simmons conducted this study with third- and fourth-grade (eight- to nine-year-old) students 
$(n=316)$ and their teachers from four cities in the urban Chicago metropolitan area. The students and teachers were asked to rate a set of 30 black and white photographs taken within the Chicago metropolitan area during early autumn. The photographs represented the variety of nature available within the Chicago metropolitan area. Scenes were taken in downtown Chicago, at schools, parks, and public spaces, and at forest preserves. The children were asked to rate the photographs on a scale of 1-5 for preference (like or dislike). The results indicated that a few of the children mentioned negative feelings of fear toward some of the scenes in the photographs. Simmons concluded that is important to understand how nature is perceived by children and in return how nature should be presented to children. The results of this study suggested that how the teacher/environmental educator introduces nature to children may well determine what, if any, environmental education goals will be met during a visit. She ended by putting the onus on the teacher/environmental educator to provide the necessary imagery, building on the overall positive views of nature held by the children while also allaying their fears.

38. Teel, T.L., Dayer, A.A., Manfredo, M.J., and Bright, A.D., 2005, Regional results from the research project entitled Wildlife Values in the West: Project report no. 58 for the Western Association of Fish and Wildlife Agencies: Fort Collins, Colorado State University, Department of Human Dimensions of Natural Resources.

Values regarding wildlife are changing in the West along with a broader societal shift that is occurring in this region of the country, according to the Colorado State University researchers, who conducted a study involving residents in 19 Western States to measure public values about wildlife. The study identified two broad categories of wildlife values. "Utilitarian" values are associated with the view that wildlife exist for human benefit - serving as resources for recreational, personal, or economic uses. These values are tied to support for and participation in recreational hunting. "Mutualist" values are represented by a sense of empathy and caring toward wildlife. They are captured in the desire for a world in which humans and wildlife can live sideby-side without fear as if part of an extended family. Results suggest that the public's values toward wildlife have been shifting more toward mutualist values and away from utilitarian values. The change is slow and occurs between generations of people. Analysis of the study would suggest that the change is due to some very basic changes in society-including increases in urbanization, economic well-being, and education. As these changes occur, people are less driven by economic or subsistence needs and become less likely to have utilitarian orientations toward wildlife.

39. Thapa, B., Graefe, A.R., and Absher, J.D., 2002, Information needs and search behaviors: A comparative study of ethnic groups in the Angeles and San Bernardino National Forests, California: Leisure Sciences, v. 24, p. 89-107.

This study used the Uses and Gratifications Theory to study how Hispanic and white forest visitors use information sources. Results showed that white visitors used all of the information sources more than Hispanic visitors. Maps and guidebooks were much less used for Hispanic than white visitors. Both groups sought information from family and friends the most. This study pointed to the importance of social groups in disseminating information and, perhaps, doing more to make all information sources more attractive to Hispanic visitors. 
40. Thompson, C.W., Aspinall, P., and Montarzino, A., 2008, The childhood factor-Adult visits to green places and the significance of childhood experiences: Environment and Behavior, $\mathrm{v}$. 40, p. 111-143.

This article explored the significance of childhood experience in woodlands and other green or natural places in relation to adult patterns of use and attitudes to such places. A questionnaire was used to explore the frequency of adults' visits to natural areas, the frequency with which they reported visiting such places as children, and their attitudes to different attributes of the places they visited. The data show a strong relationship between frequent childhood visits and being prepared to visit woodlands or green spaces alone as an adult. By contrast, not visiting as a child was associated with a very low likelihood of later adult visits. The data also suggested that the physical and the emotional benefits of access to green space are strongly reflected in childhood experience. The significance of these findings for today's children, as they become adults, was also discussed. The frequency of people's visits to natural areas in childhood, as reported by adults, was reported as a strong predictor of adult patterns of open-space use. The highly significant results from the data across two distinct projects suggested that this may be one of the key factors in understanding adult behavior and attitudes in relation to natural areas and that this may have wider implications for people's health and wellbeing. Frequency of childhood visits not only predicts frequency of adult visits to woodlands and green places in general but also is associated with other important attitudes and behavior.

41. Tierney, P.T., Dahl, R., and Chavez, D., 2001, Cultural diversity in use of undeveloped natural areas by Los Angeles county residents: Tourism Management, v. 22, p. 271-277.

This research looked at Los Angeles residents and their tendency to visit or not visit local natural areas. They found that only two out of five locals visited undeveloped natural areas during the summer vacation period. They looked at white, African-American, Hispanic, and Asian or Pacific Islander groups to see if there were differences in perceived constraints to visitation. While differences were slight, what was interesting was that three constraints, while not seen as constraints by the groups, had significant differences between white respondents and all other groups. This means that, even though these were not seen as major constraints, they were seen as more of a barrier to the minority group members than to the dominant group. These constraints were (1) would travel if more workers of my ethnicity were employed there, (2) people of my ethnicity are discriminated against when traveling, and (3) don't feel welcome when traveling.

42. Urban, M., and Martin, K., 2008, Developing environmentally responsible behavior-A case study of Trailside Discovery Camp: Camping Magazine, retrieved August 20, 2009, at http://www.acacamps.org/campmag/issues/0807/research.php.

Using the Children's Environmental Attitudes and Knowledge Scale (CHEAKS), the authors examined the relationship between attending summer camp and environmentally responsible attitudes and behavior. Participants included 136 students who were tested at the beginning of attendance at Trailside Discovery Camp in Anchorage, Alaska, and approximately one month after the end of camp. Results indicated a relationship between the amount of knowledge the children had and their attitudes and behaviors toward the environment. 
43. Vaske, J.J., and Kobrin, K.C., 2001, Place attachment and environmentally responsible behavior: The Journal of Environmental Education, v. 32, p. 16-21.

This article illustrated how an attachment to a local natural resource can influence environmentally responsible behavior (ERB) in an individual's everyday life. Data for this study were obtained from an onsite survey distributed to youth 14-17 years of age, who participated in local, natural-resource-based work programs $(\mathrm{n}=182)$. Four variables were used to measure Environmentally Responsible Behavior: (1) Learning how to solve environmental issues, (2) talking with others about environmental issues, (3) trying to convince friends to act responsibly, and (4) talking with parents about the environment. Following previous research, the authors operationalized place attachment using two concepts: (1) Place dependence (that is, a functional attachment) and (2) place identity (that is, an emotional attachment). The influence of these two concepts on ERB was examined using a structural equation model. Data for this analysis were obtained from a survey of youth $(\mathrm{n}=182)$, who participated in local natural-resource work programs. As hypothesized, place identity mediated the relationship between place dependence and responsible behavior. The authors found that place dependence influenced place identity, and place identity was significantly related to ERB. Overall, the article concluded with the suggestion that encouraging an individual's connection to a natural setting facilitates the development of general ERB.

44. West, P.C., 1989, Urban region parks and black minorities - Subculture, marginality, and interracial relations in park use in the Detroit metropolitan area: Leisure Sciences, v. 11, p. $11-28$.

While the marginality and ethnicity hypotheses have dominated recreation literature, West argued that there is another potential explanation for limited minority participationintercultural communication. When diverse cultures come together, there can be instances of conflict over miscommunication. Issues of racism and prejudice at recreation areas are the obvious examples of this phenomenon, but even subtle stereotypes and comments can influence the atmosphere of the area.

Publishing support provided by:

Denver Publishing Service Center

For more information concerning this publication, contact:

Center Director, USGS Fort Collins Science Center

2150 Centre Ave., Bldg. C

Fort Collins, CO 80526-8118

(970) 226-9398

Or visit the Fort Collins Science Center Web site at: http://www.fort.usgs.gov/ 